\title{
Impact of Ion Irradiation upon Structure and Magnetic Properties of NANOPERM-Type Amorphous and Nanocrystalline Alloys
}

\author{
Marcel Miglierini ${ }^{1,2}$ and Mariusz Hasiak ${ }^{3}$ \\ ${ }^{1}$ Institute of Nuclear and Physical Engineering, Slovak University of Technology in Bratislava, Ilkovičova 3, 81219 Bratislava, Slovakia \\ ${ }^{2}$ Department of Nuclear Reactors, Faculty of Nuclear Sciences and Physical Engineering, Czech Technical University in Prague, \\ $V$ Holešovičkách 2, 18000 Prague 8, Czech Republic \\ ${ }^{3}$ Department of Mechanics and Materials Science, Wrocław University of Technology, Smoluchowskiego 25, 50-370 Wrocław, Poland
}

Correspondence should be addressed to Marcel Miglierini; marcel.miglierini@stuba.sk

Received 11 January 2015; Accepted 2 June 2015

Academic Editor: Alireza Khataee

Copyright (c) 2015 M. Miglierini and M. Hasiak. This is an open access article distributed under the Creative Commons Attribution License, which permits unrestricted use, distribution, and reproduction in any medium, provided the original work is properly cited.

\begin{abstract}
Structural modifications and their impact upon magnetic properties are studied in amorphous and nanocrystalline NANOPERMtype ${ }^{57} \mathrm{Fe}_{75} \mathrm{Mo}_{8} \mathrm{Cu}_{1} \mathrm{~B}_{16}$ alloy. They are introduced by irradiation with $130 \mathrm{keV} \mathrm{N}{ }^{+}$ions to the total fluencies of up to $2.5 \times 10^{17}$ ions $/ \mathrm{cm}^{2}$ under different cooling conditions. Increased temperature during the irradiation triggers formation of nanocrystallites of bcc-Fe in those subsurface regions that are affected by bombarding ions. No crystallization occurs when good thermal contact between the irradiated sample and a sample holder is assured. Instead, structural rearrangement which favours development of magnetically active regions was determined by the local probe methods of Mössbauer spectrometry. Dipole magnetic interactions dominate in subsurface regions on that side of the ribbons which was exposed to ion irradiation. Nevertheless, structural modifications demonstrate themselves also via macroscopic magnetic parameters such as temperature dependence of magnetization, Curie temperature, and hysteresis loops. Impact of only the temperature itself to the observed effects is assessed by the help of samples that were subjected just to heat treatment, that is, without ion irradiation.
\end{abstract}

\section{Introduction}

New demands of the market as well as developing ecological attitude of the society require a use of progressive technologies and advanced materials [1]. This responds to recent demands regarding cutting-edge basic research related to energy, applied physics, and materials science. Particularly the latter tends to contribute to understanding of the materials properties under harsh external conditions like, for example, enhanced radiation background which is frequently observed in nuclear installations.

Fe-based metallic glasses (MGs) belong to a class of amorphous materials $[2,3]$ that, though introduced already couple of decades ago, are still attractive because of their unique magnetic [4] as well as mechanical [5] properties. Recently, they were considered as hot candidates for magnetic cores of accelerator RF-cavities to improve their performance [6]. At this particular application, they are exposed to ion irradiation caused by beam losses. At high primary-beam intensities, even low beam losses may lead to rather high radiation doses delivered to the magnetic materials. Though it was shown by transmission electron microscopy that MGs irradiated by thermal neutrons remain amorphous [7], the experimental results obtained have indicated that ion bombardment can induce structural changes within the disordered atomic arrangement of MGs which consequently affects their physical properties. Because MGs were considered as appropriate materials in radiation-exposed environments, one has to pay due attention to the effects of enhanced irradiation.

Indeed, the irradiation of a $\mathrm{Fe}_{90} \mathrm{Zr}_{10}$ amorphous alloy with $209 \mathrm{MeV}^{84} \mathrm{Kr}$ ions with the fluence of $3 \times 10^{14}$ ions $/ \mathrm{cm}^{2}$ exhibited pronounced changes in magnetic hyperfine interactions as derived from Mössbauer spectra [8]. The modification of the magnetic anisotropy was observed in ferromagnetic $\mathrm{Fe}_{78} \mathrm{~B}_{13} \mathrm{Si}_{9}$ and $\mathrm{Fe}_{40} \mathrm{Ni}_{38} \mathrm{Mo}_{4} \mathrm{~B}_{18}$ MGs after irradiation 
by swift heavy ${ }^{127} \mathrm{I}$ ions with the energy of $100 \mathrm{MeV}$ at different fluencies from $5 \times 10^{12}$ to $7.5 \times 10^{13}$ ions $/ \mathrm{cm}^{2}$ [9]. The magnetic anisotropy has been studied by measuring the relative intensity ratio of Mössbauer sextets.

On the other hand, the irradiation with $120 \mathrm{MeV} \mathrm{Ag}$ and $350 \mathrm{MeV} \mathrm{Au}$ ions of $\mathrm{Fe}_{0.85} \mathrm{~N}_{0.15}$ and $\mathrm{Fe}_{73.9} \mathrm{Cu}_{0.9} \mathrm{Nb}_{3.1} \mathrm{Si}_{13.2} \mathrm{~B}_{8.9}$ amorphous films resulted in gradual removal of anisotropy and a decrease in coercivity, which was attributed to relaxation of internal stresses [10]. This demonstrates that swift heavy-ions can be used for controlled modification of magnetic properties of thin films. At the fluence of $5 \times 10^{13}$ ions $/ \mathrm{cm}^{2}$ the in-plane anisotropy completely disappeared.

Apart from amorphous materials, the influence of ion irradiation is studied also upon crystalline materials. As an example, we mention the recent reports of $\mathrm{Be}-\mathrm{Fe}-\mathrm{Be}$ threelayer alloy irradiated with $40 \mathrm{keV}$ helium ions up to doses of $1 \times 10^{17}, 1 \times 10^{18}$, and $2 \times 10^{18}$ ions $/ \mathrm{cm}^{2}[11,12]$ that is foreseen for production of a primary wall for fusion reactors.

In general, it can be stated that ion irradiation of MGs may influence their thermal stability, crystallization processes [13], magnetic anisotropy [14], shapes of hysteresis loops [15], Curie temperatures [16], surface crystallization [17], and so forth.

Along with possible use of MGs as magnetic shielding, sensors, transformer cores, and so forth [18] that is benefiting from their excellent magnetic properties, they are also considered for use in nuclear facilities. The long-term reliability of structural nuclear materials operating in tough surroundings of intense radiation and high temperature and in the presence of corrosion agents is an important technologic, economic, and environmental demand, and it raises a number of challenges. Currently, in spite of the research efforts around the world, the ability to design, engineer, and predict the performance of new materials in such extreme environments is still beyond the current knowledge, and a dedicated research to understand their distinctive physical properties is needed to better realize the fundamental mechanisms involved in these processes, which will also have a very positive effect in other areas of research and technology such as the solar cells or space electronics.

It should be mentioned that selected MGs are used as precursors for preparation of nanocrystalline alloys that exhibit magnetic parameters superior to those of the original MGs $[4,19]$. They belong to the families of the so-called FINEMET [20], NANOPERM [21], and HITPERM [22] alloys. Nanocrystalline metallic alloys (NCAs) represent a new class of nanocomposite materials the physical properties of which can be tailored not only by controlling their chemical composition but also by varying the size of crystalline grains, their morphology, and structural arrangement [23]. They can be effectively prepared by controlled crystallization of MGs with appropriate composition. The size of the structural elements (nanocrystals) dominantly influences mechanical, optical, electrical, and/or magnetic properties. Disordered nature of structural arrangement in nanocrystalline alloys gives rise to advantageous (from the point of view of practical application) magnetic properties
[24]. Particularly, nanocrystalline alloys have attracted a lot of scientific interest because, contrary to their amorphous counterparts, their magnetic parameters do not substantially deteriorate at elevated temperature during their practical exploitation.

One may suppose that all changes of macroscopic characteristics discussed above are somehow connected to local structural variations of MGs and NCAs that can be, in turn, modified by ion irradiation. However, the atomic arrangement in these disordered alloys is not well understood at present unlike the well-defined long-range order in crystalline materials. Thus, their structural characterization at the atomic level represents an ambitious mission requiring advanced experimental techniques such as those using very intense X-rays produced by the latest generation of synchrotron radiation sources [25].

In order to unveil the correlation between structural arrangement and resulting magnetic properties, here we employ a local probe method, namely, the Mössbauer spectrometry (MS). It directly correlates the magnetic states of materials with their structure $[26,27]$ via hyperfine interactions and their distributions. In particular, we concentrate on surface regions in ribbon-shaped samples exposed to ion bombardment with $\mathrm{N}^{+}$ions. In doing so, we actually extend our recent study [17] towards characterization of deeper subsurface regions by employing the technique of Conversion X-ray Mössbauer Spectrometry (CXMS) in addition to more frequently used Conversion Electron Mössbauer Spectrometry (CEMS). The MS investigations are complemented by magnetic measurements that provide integral information derived from the whole bulk of the alloy.

Because of the technique of Mössbauer spectrometry which is especially suitable for identification of subtle structural changes even in disordered system, we have decided to use a NANOPERM-type alloy with a suitable composition, namely, ${ }^{57} \mathrm{Fe}_{75} \mathrm{Mo}_{8} \mathrm{Cu}_{1} \mathrm{~B}_{16}$ whose Mössbauer spectrum is far simpler than that of either FINEMET or HITPERM alloy. Particularly in nanocrystalline alloys, spectral components that belong to structurally different atomic positions, namely, amorphous matrix, nanocrystalline grains, and interface regions (surfaces of the nanograins), can be readily recognized $[28,29]$. At the same time, without any loss of generality this system can serve as an appropriate representative of this class of materials.

\section{Materials and Methods}

Amorphous ${ }^{57} \mathrm{Fe}_{75} \mathrm{Mo}_{8} \mathrm{Cu}_{1} \mathrm{~B}_{16}$ metallic glass was prepared by the method of rapid quenching of a melt upon rotating wheel in a form of ribbons. The casting was done in the air; that is, no protective atmosphere was used. The width and the thickness of the ribbons were of about $1 \mathrm{~mm}$ and $20 \mu \mathrm{m}$, respectively. The side of the ribbon which was in direct contact with the quenching wheel will be referred to as wheel side. The opposite side, that is, the one exposed to the surrounding atmosphere during the production process, will be called the air side. Chemical composition of the alloy was checked by optical emission spectrometry with inductively coupled 
plasma (Mo, B) and flame atomic absorption spectrometry $(\mathrm{Fe}, \mathrm{Cu})$.

The as-quenched alloys were irradiated using $130 \mathrm{keV}$ nitrogen ions into the air side of the ribbons with the fluencies of up to $2.5 \times 10^{17}$ ions $/ \mathrm{cm}^{2}$. During the irradiation, several strips of $1 \times 12 \mathrm{~mm}^{2}$ ribbons were firmly attached to aluminium holders. We have used double-sided adhesive tape over the entire samples' surface area in order to ensure good thermal contact with a cooled support. In this way, the temperature of the irradiated ribbons was kept sufficiently low to eliminate thermally induced effects. In order to check the influence of an increased temperature during the ion irradiation, some samples were attached to the holder only with Kapton sticky tape that was applied over small samples' exterior at the edges of the strips. In both cases, the sample holder was cooled during the irradiation by thermal conduction using liquid nitrogen.

The maximum penetration depth of the nitrogen ions was determined by simulations performed in a "full cascade" mode with the SRIM supporting software [30]. The maxima of radiation damage profile and the ion penetration range distribution are located at $\sim 130 \mathrm{~nm}$ and $\sim 180 \mathrm{~nm}$, respectively. The mean projected range is $148 \mathrm{~nm}$ and the range straggling is $51 \mathrm{~nm}$. So, the radiation damage caused by $\mathrm{N}^{+}$ions is positioned closer to the samples' surface.

The effect of the temperature alone was studied upon asquenched samples that were directly annealed without ion irradiation. Several pieces of MGs were thermally treated for $30 \mathrm{~min}$ in a vacuum at 643,723 , and $783 \mathrm{~K}$ which are close to the onset of crystallization $T_{x 1}=735 \mathrm{~K}$. The latter was determined by differential scanning calorimetry (DSC). These heat treatments produced partial crystallization. Subsequently, nanocrystalline alloys were formed.

The structural characterization of the investigated alloys was accomplished by the techniques of Mössbauer spectrometry that are sensitive particularly to subsurface regions. Namely, we have employed Conversion Electron Mössbauer Spectrometry (CEMS) and Conversion X-ray Mössbauer Spectrometry (CXMS). They provide information from the depths of $\sim 200 \mathrm{~nm}$ and $\sim 5-10 \mu \mathrm{m}$, respectively. Our samples were produced from iron enriched to about $50 \%$ in the ${ }^{57} \mathrm{Fe}$ isotope that facilitates the use of the CEMS and CXMS techniques. Mössbauer effect experiments were performed with a constant acceleration spectrometer using a ${ }^{57} \mathrm{Co} / \mathrm{Rh}$ source. Calibration was done using a thin $(12.5 \mu \mathrm{m}) \alpha$-Fe foil. Evaluation of the spectra was accomplished by the Confit software [31]. The obtained isomer shift values are quoted with respect to a room temperature Mössbauer spectrum of the calibration $\alpha$-Fe foil.

Magnetic characteristics were obtained with the help of a VersaLab system (Quantum Design). Magnetization per unit mass (i.e., specific magnetization, $M$ ) as a function of temperature $(T)$ and/or external magnetic field (i.e., magnetizing flux density, $\mu_{0} H$ ) were recorded in the temperature range $50-400 \mathrm{~K}$. The DC hysteresis loops were measured for the magnetizing flux density up to $\mu_{0} H=50 \mathrm{mT}$ in the temperature range from $50 \mathrm{~K}$ up to $400 \mathrm{~K}$. The $M(T)$ curves for all investigated samples were recorded at zero field cooling
(ZFC) and field cooling (FC) conditions for four values of the external magnetic field; that is, $\mu_{0} H=2.5 \mathrm{mT}, 5 \mathrm{mT}, 10 \mathrm{mT}$ and $0.1 \mathrm{~T}$.

\section{Results and Discussion}

\subsection{Mössbauer Spectrometry}

3.1.1. Ion Irradiation: Good Thermal Contact between Sample and Cooled Sample Holder. The as-quenched ${ }^{57} \mathrm{Fe}_{75} \mathrm{Mo}_{8} \mathrm{Cu}_{1} \mathrm{~B}_{16}$ metallic glass exhibits amorphous structure which is characterized by broadened Mössbauer spectral lines. Room temperature CEMS spectrum taken from the air side of the ribbon-shaped sample is presented in Figure 1(a). Nevertheless, because the lines do not show clear evidence of either doublet- or sextet-like forms one can expect a combination of both electric quadrupole and magnetic dipole hyperfine interactions, respectively, which are of a comparable strength. Consequently, the experimental data (full symbols in Figure 1(a)) was refined by the help of two spectral components. The overall theoretical fit is plotted in Figure 1 (and also in the other figures with Mössbauer spectra) by red solid line.

One spectral component represents nonmagnetic regions of the as-quenched alloy. They were reconstructed by a distributed doublet (dark grey subspectrum in Figure 1(a)) using distribution of quadrupole splitting $P(Q S)$ which is plotted in Figure 1(b). The second (light grey) spectral component is assigned to those parts of the amorphous structure that exhibit weak magnetic hyperfine interactions. The corresponding sextets have very low hyperfine magnetic fields as it is demonstrated by their resultant distribution $P(B)$ in Figure 1(c). CEMS spectrum in Figure 1(a) suggests that the investigated system has close-to-room Curie temperature $T_{C}$ in the as-quenched state. Indeed, in our recent work we have determined $T_{C}=313 \mathrm{~K}$ [32] for this MG using temperature dependence of magnetization.

After ion irradiation, relative contribution of the magnetic regions has increased. Figure 1(d) shows the situation for the highest fluence of $2.5 \times 10^{17}$ ions $/ \mathrm{cm}^{2}$. CEMS spectrum taken from the air side of the ribbon, that is, the one which was exposed to ion bombardment, has apparently broadened and exhibits quite well resolved sextet. The corresponding $P(B)$ distribution in Figure 1(f) extends over notably higher hyperfine magnetic fields. Consequently, the nonmagnetic regions are also polarized which is seen by considerably increased QS-values in Figure 1(e) as compared to the nonirradiated as-quenched state.

We should mention also small ( $\sim 7 \%)$ spectral component that consists of two sextets. They are plotted in Figure 1(d) in green colours and have been found only in this sample with the CEMS experiment. The corresponding spectral parameters of isomer shifts and hyperfine fields of 0.31 , $0.54 \mathrm{~mm} / \mathrm{s}$ and $47.04,42.13 \mathrm{~T}$, respectively, indicate that they belong most probably to magnetite with not well developed structure and possible impurity inclusions. Its occurrence might be caused by the reaction with residual oxygen from the vacuum. It is noteworthy that CEMS experiments are 


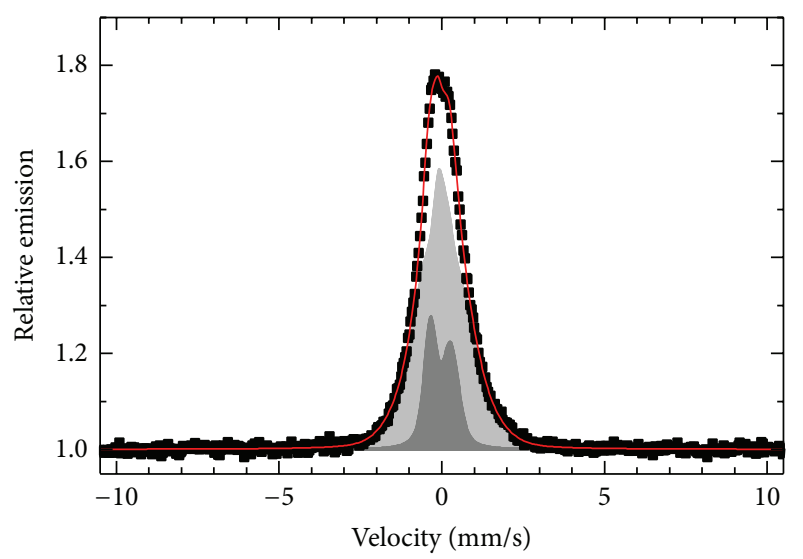

(a)

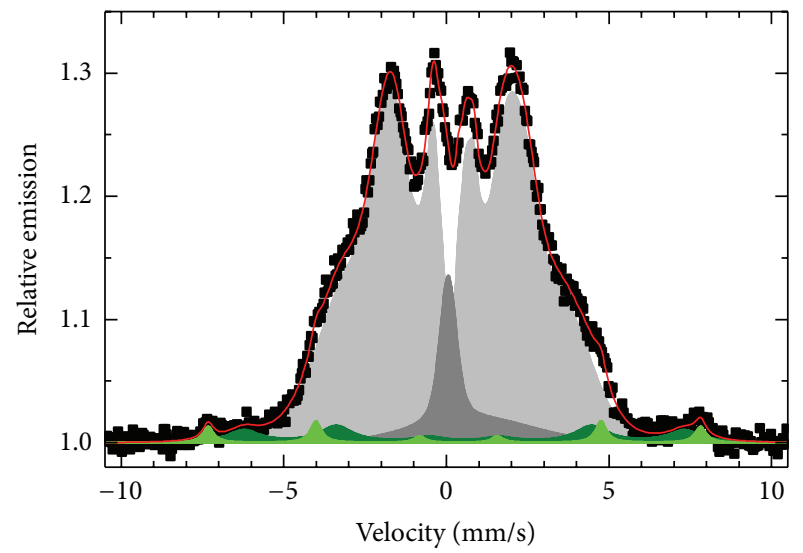

(d)

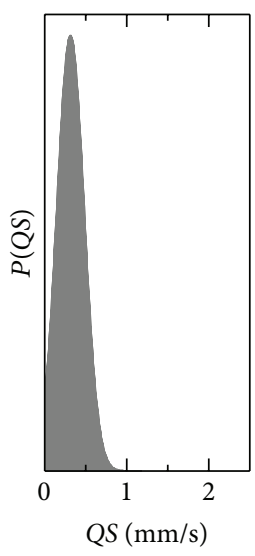

(b)

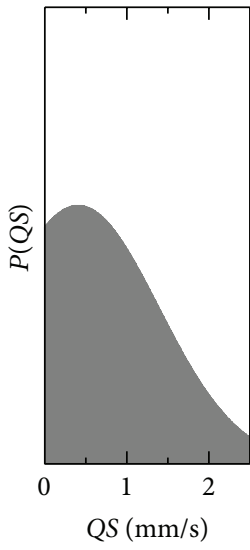

(e)

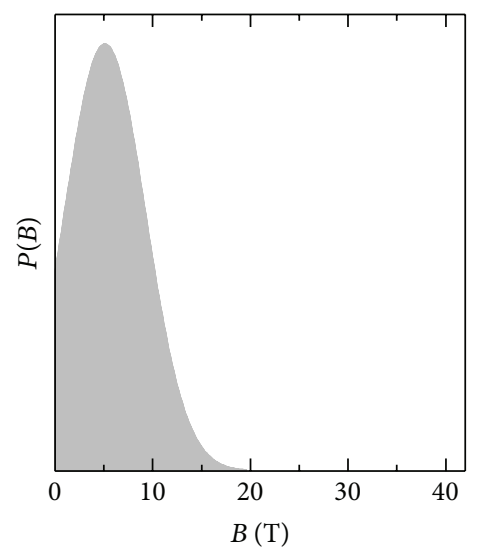

(c)

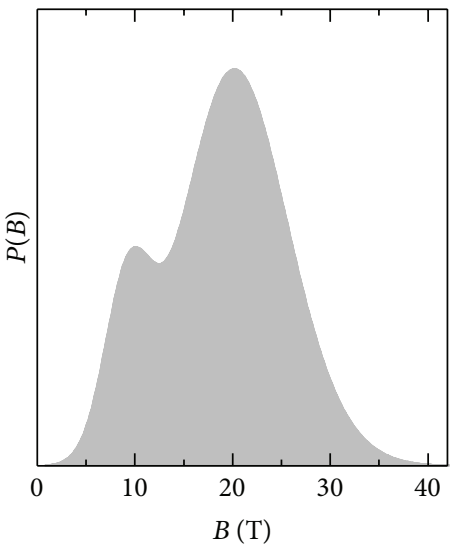

(f)

FIGURE 1: CEMS Mössbauer spectra of the ${ }^{57} \mathrm{Fe}_{75} \mathrm{Mo}_{8} \mathrm{Cu}_{1} \mathrm{~B}_{16}$ alloy in the as-quenched state (a) with the corresponding $P(Q S)(\mathrm{b})$ and $P(B)$ (c) distributions and after irradiation with $2.5 \times 10^{17}$ ions $/ \mathrm{cm}^{2}$ (d) with the corresponding $P(Q S)$ (e) and $P(B)$ (f) distributions as obtained from the air side of the ribbons.

sensitive only to subsurface regions down to the depth of $\sim 200 \mathrm{~nm}$.

The situation at the wheel side of the ribbons, that is, the one that was not exposed to the ion irradiation, is shown in Figure 2. Both the CEMS spectra taken from the as-quenched (Figure 2(a)) and irradiated (Figure 2(d)) specimens are very alike to that from Figure 1(a). Quantitative assessment unveils slightly higher average hyperfine field at the as-quenched wheel side $(6.16 \mathrm{~T})$ as compared to the air side $(5.11 \mathrm{~T})$. Its relative fraction is also higher, namely, $82 \%$ versus $77 \%$. As far as the average quadrupole splitting value is concerned, it is higher too at the wheel side $(0.75 \mathrm{~mm} / \mathrm{s})$ than at the air side $(0.63 \mathrm{~mm} / \mathrm{s})$. All this indicates that, in the as-quenched state, magnetically active regions predominantly appear at the wheel side of the ribbons.

If we compare the wheel side of the as-quenched alloy to that one which was subjected to the highest ion fluence of $2.5 \times 10^{17}$ ions $/ \mathrm{cm}^{2}$ we observe slight increase in the average hyperfine field from $6.16 \mathrm{~T}$ to $7.15 \mathrm{~T}$ but on account of its relative fraction which has dropped from $82 \%$ to $73 \%$. Note the error margins of $\pm 0.15 \mathrm{~T}$ and $\pm 2 \%$ for hyperfine field and relative fraction, respectively. Nevertheless, no appreciable change was found in the average quadrupole splitting value that was $0.75 \mathrm{~mm} / \mathrm{s}$ in the as-quenched state and $0.76 \mathrm{~mm} / \mathrm{s}$ after the irradiation while its error margin is $\pm 0.04 \mathrm{~mm} / \mathrm{s}$.

Let us remind that the ions were implanted into the air side of the ribbons and their calculated penetration depth is about $180 \mathrm{~nm}$, that is, within the regions that could be seen by the CEMS techniques $(<200 \mathrm{~nm})$. In fact, our choice of the irradiation ions from the point of view of their type and energy, and consequently from their projected range of radiation damage, was purposely motivated namely by the applied method of CEMS. So one can conclude that the effects of ion irradiation dominate at the air side through which the ions have penetrated into the material and the opposite wheel side is practically intact.

Similar observations can be made when the CXMS method is applied which scans the material to more deep regions of about $5-10 \mu \mathrm{m}$. Mössbauer spectra of all ion irradiated samples which were recorded from the air sides by CEMS and CXMS techniques are demonstrated in Figure 3.

We can see the same tendency of spectrum broadening with the increasing fluence also for deeper regions inside the material as demonstrated by the CXMS spectra in 


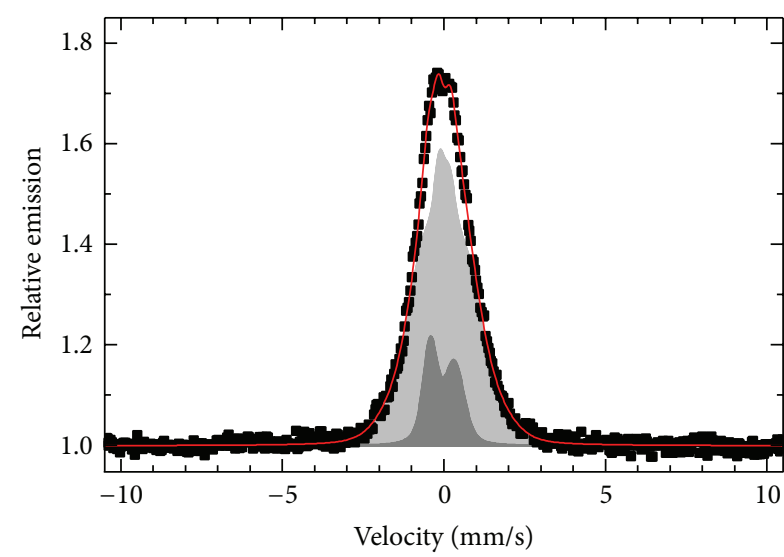

(a)

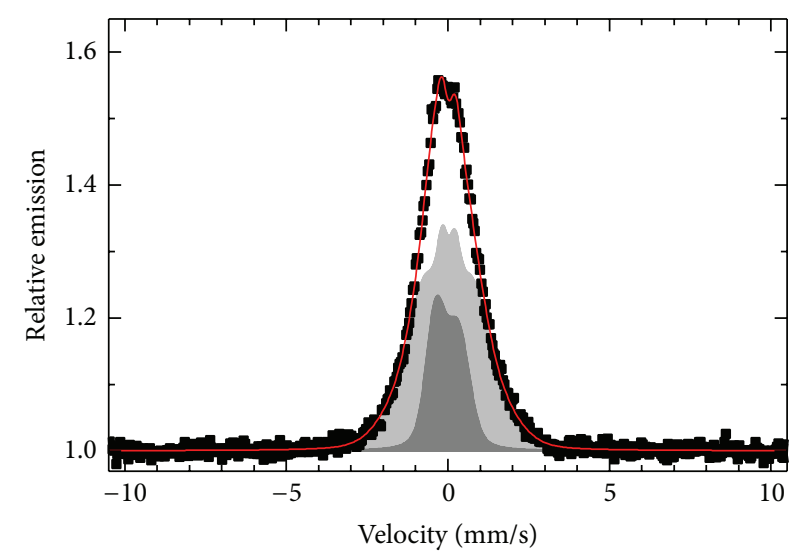

(d)

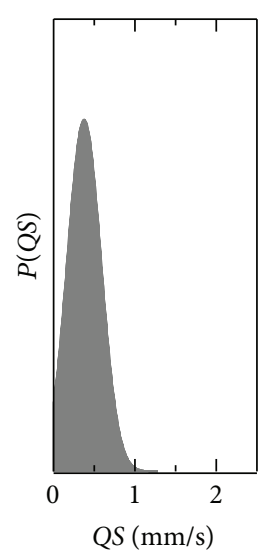

(b)

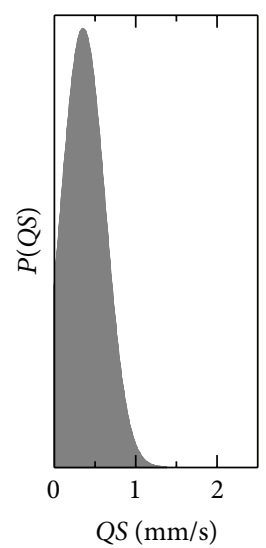

(e)

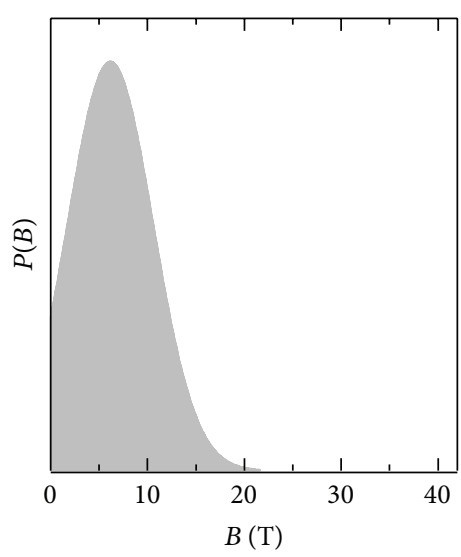

(c)

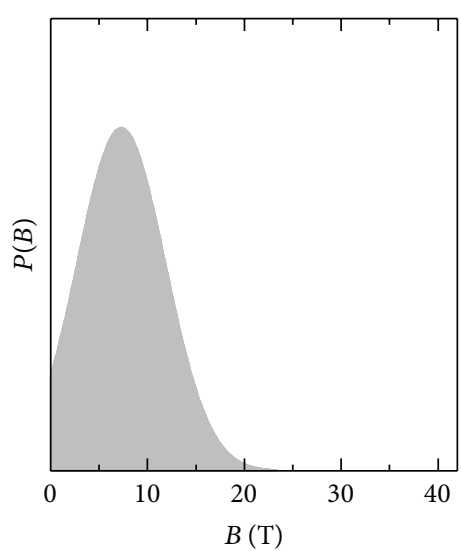

(f)

Figure 2: CEMS Mössbauer spectra of the ${ }^{57} \mathrm{Fe}_{75} \mathrm{Mo}_{8} \mathrm{Cu}_{1} \mathrm{~B}_{16}$ alloy in the as-quenched state (a) with the corresponding $P(Q S)(\mathrm{b})$ and $P(B)$ (c) distributions and after irradiation with $2.5 \times 10^{17}$ ions $/ \mathrm{cm}^{2}$ (d) with the corresponding $P(Q S)$ (e) and $P(B)$ (f) distributions as obtained from the wheel side of the ribbons.

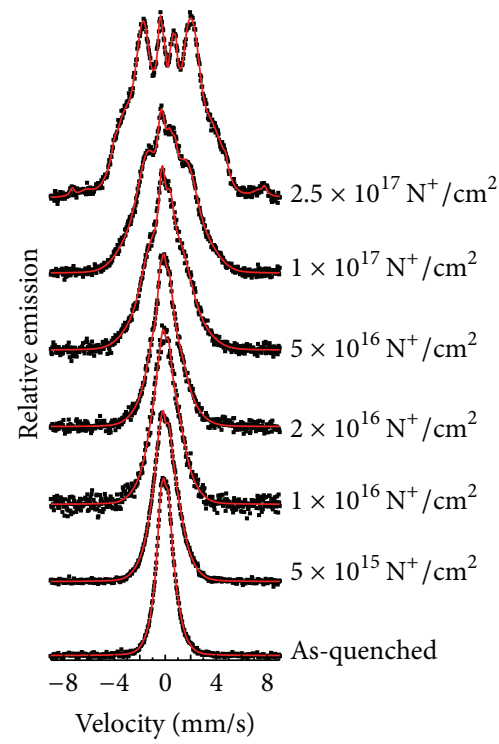

(a)

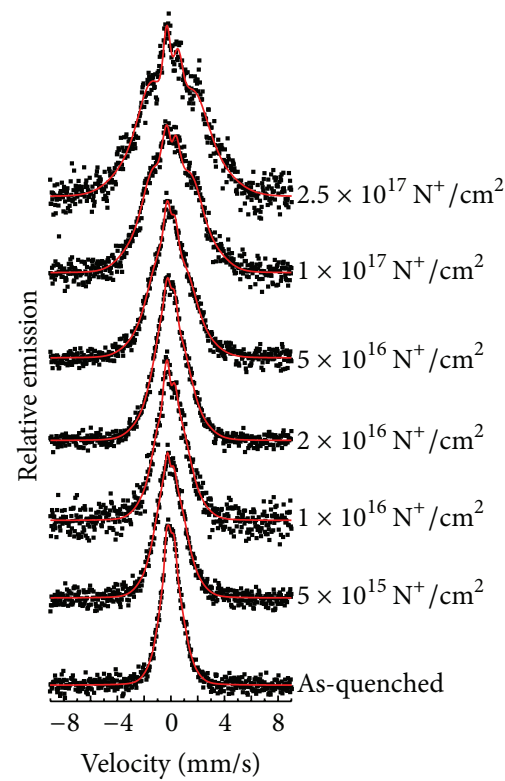

(b)

Figure 3: CEMS (a) and CXMS (b) spectra of the ${ }^{57} \mathrm{Fe}_{75} \mathrm{Mo}_{8} \mathrm{Cu}_{1} \mathrm{~B}_{16}$ alloy that were taken from the air side after the irradiation with the indicated fluencies. 


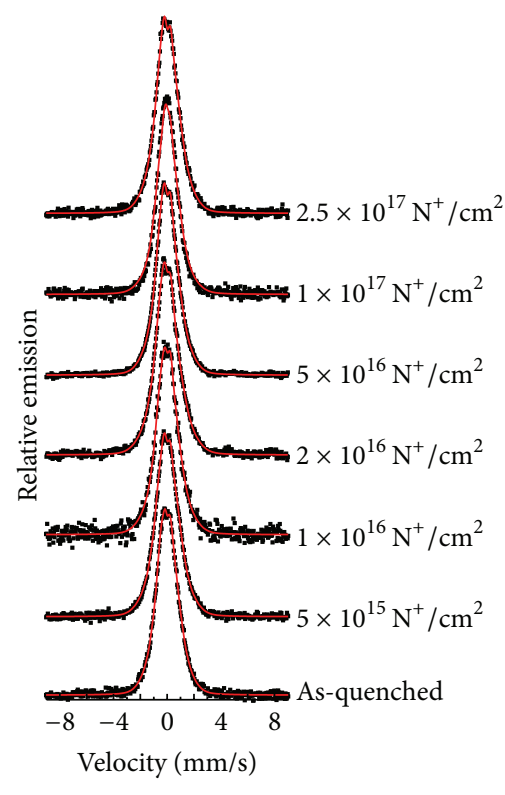

(a)

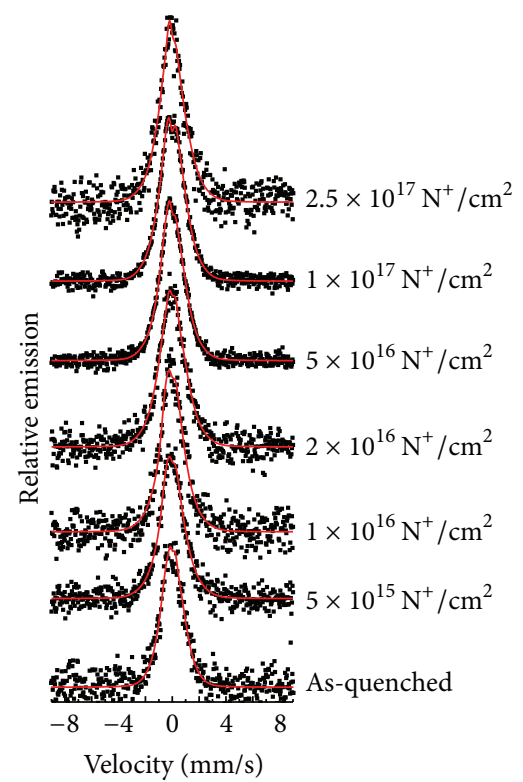

(b)

FIGURE 4: CEMS (a) and CXMS (b) spectra of the ${ }^{57} \mathrm{Fe}_{75} \mathrm{Mo}_{8} \mathrm{Cu}_{1} \mathrm{~B}_{16}$ alloy that were taken from the wheel side after the irradiation with the indicated fluencies.

Figure $3(\mathrm{~b})$. This indicates a rising importance of magnetically active areas. We assume that they were introduced by structural modifications though these are confined mostly to the depths of less than $180 \mathrm{~nm}$ as suggested by the SRIM calculations. Nevertheless, changes in the magnetic microstructure affect the associated hyperfine interactions in such a way that they extend beyond the predicted range of the radiation damage profile.

Mössbauer spectra shown in Figure 4 were recorded by CEMS and CXMS techniques from the wheel sides of the samples. As it was expected, qualitatively they do not differ one from another regardless the irradiation fluence and/or scanning depth. All spectra exhibit almost the same line shape. Consequently, the same fitting model consisting of distributions of quadrupole splitting $P(Q S)$ and distribution of hyperfine magnetic fields $P(B)$ was adopted.

Mössbauer spectral parameters related to $P(B)$ and $P(Q S)$ distributions were derived from the theoretically calculated and refined fits (red solid lines) to the experimental data (full symbols) presented in Figures 3 and 4 . They comprise the average hyperfine magnetic field and the quadrupole splitting values, respectively, together with their corresponding average isomer shifts. The average hyperfine magnetic fields and isomer shifts of the magnetic spectral components are plotted against the applied fluence in Figure 5. Here, the results obtained from both the air and the wheel sides of the ribbons using CEMS as well as CXMS methods are presented.

Considerable increase of the average hyperfine magnetic field is observed at the air side (Figure 5(a)) when ion irradiation was applied. The magnetically active regions seem to be predominantly located closer to the sample's surface after the impact of ions with the fluence higher than $5 \times$ $10^{16}$ ions $/ \mathrm{cm}^{2}$. The associated isomer shifts in Figure 5(b) show also gradual increase with ion fluence. The observed effects could be due to changes in chemical short-range order arrangements that are introduced by the bombarding ions. It should be noted that the maximum penetration depth of the $130 \mathrm{keV} \mathrm{N}^{+}$ions was calculated to be $\sim 180 \mathrm{~nm}$ which falls exactly into the subsurface regions screened by CEMS.

Only a minor increase in hyperfine magnetic fields is demonstrated in Figure 5(c) after the irradiation with respect to the as-quenched state and the new values are almost equal (within the error range) regardless the applied fluence. This indicates that at the wheel side the effects of ion bombardment are negligible and they could not be associated with chemical rearrangement of the atoms due to ion mixing. This assumption is supported by isomer shifts in Figure 5(d) that fluctuate around zero value and do not exceed over the error margin.

Figure 6 summarizes the hyperfine spectral parameters related to the nonmagnetic $P(Q S)$ components which are characterized by the average quadrupole splitting values and their corresponding isomer shifts. At the air side, an increase of the average quadrupole splitting is observed in Figure 6(a) after the irradiation when compared to the as-quenched state of the alloy. Nevertheless, it is stabilized over the entire range of fluencies for both CEMS and CXMS experiments, that is, for different depths of the investigated material. On the other hand, the isomer shift values in Figure 6(b) ascend dramatically in the near subsurface regions that are scanned by CEMS while they are falling down with rising fluence in more deep sample areas as unveiled by CXMS. The observed changes can be associated with chemical short-range order rearrangement caused by ion mixing.

Similarly as in the case of hyperfine magnetic fields, the average quadrupole splitting at the wheel side in Figure 6(c) 


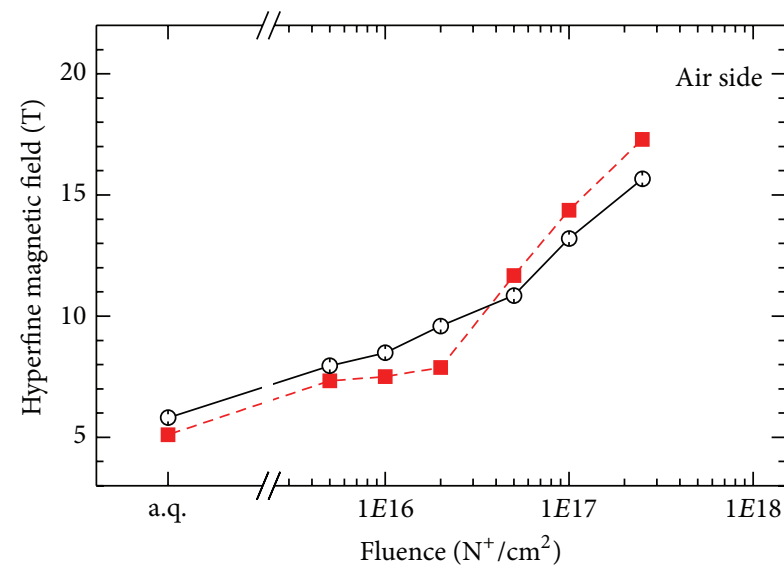

(a)

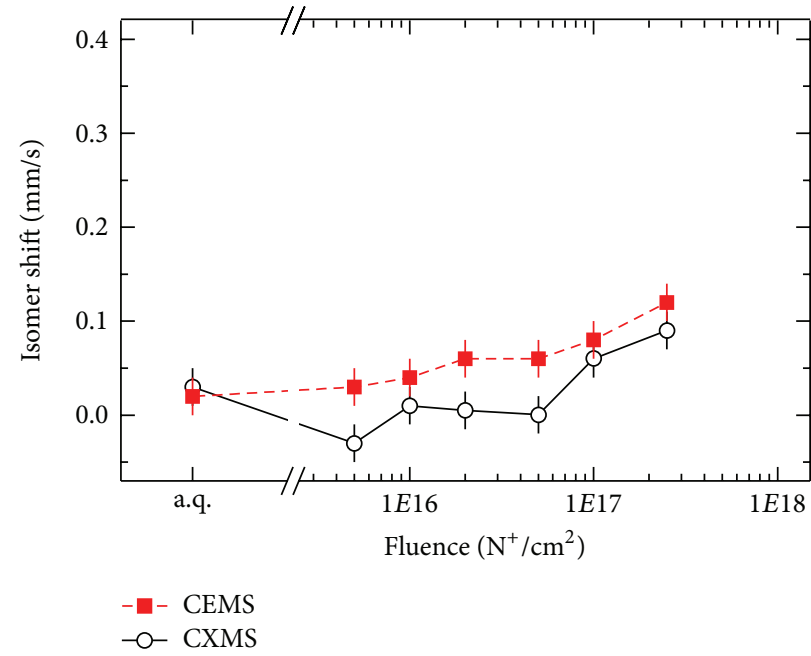

(b)

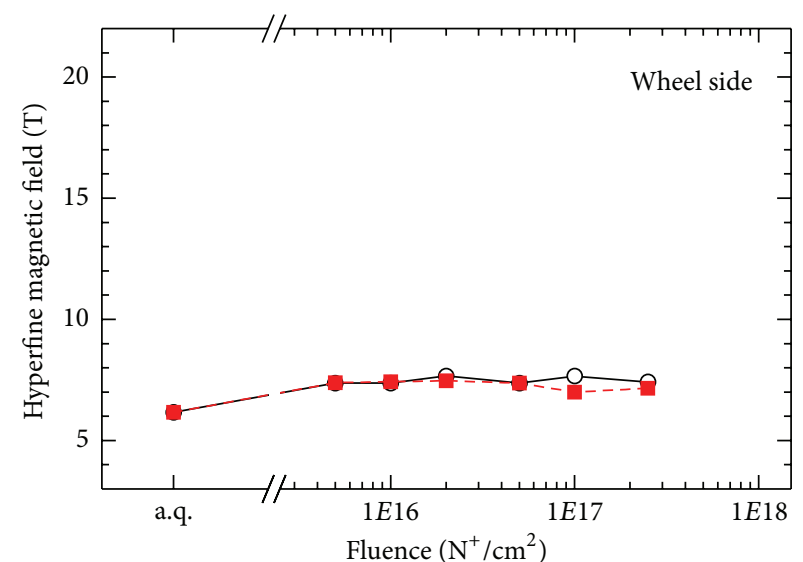

(c)

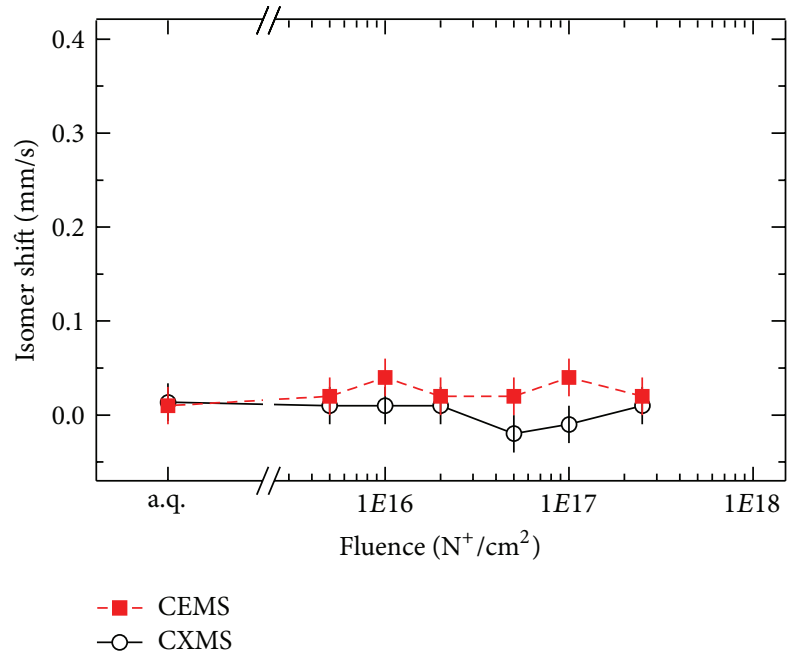

(d)

Figure 5: Average hyperfine magnetic fields ( $a, c)$ and their corresponding isomer shifts (b, d) obtained from the CEMS (full red squares) and CXMS (opened black circles) spectra of the ${ }^{57} \mathrm{Fe}_{75} \mathrm{Mo}_{8} \mathrm{Cu}_{1} \mathrm{~B}_{16}$ alloy that were taken from the air $(\mathrm{a}, \mathrm{b})$ and from the wheel $(\mathrm{c}, \mathrm{d})$ sides plotted against the irradiation fluence (a.q. = as-quenched). The connecting lines are only guides to the eye.

does not show appreciable differences between the asquenched and the irradiated samples when assessed separately for the CEMS and CXMS experiments. Isomer shift values in Figure 6(d) are almost unchanged as well.

Relative fractions of $P(B)$ and $P(Q S)$ distributions derived from the CEMS and CXMS experiments performed for both sides of the ribbon-shaped samples are plotted versus fluence in Figure 7. Note that the error bars are nearly identical with the size of the symbols. At the air side, magnetic regions that are represented by $P(B)$ distributions show in Figure 7 (a) rising tendency with the fluence on account of the nonmagnetic $P(Q S)$ areas. This holds for both the CEMS and CXMS results. At the wheel side (Figure 7(b)), an opposite trend is observed.

In order to facilitate mutual comparison of the evolution of the particular spectral parameters with fluence for the air and the wheel sides we provide the obtained results in another way of their presentation. They are displayed in Figures 8 and 9 for different depths of the samples as they were screened by CEMS and CXMS experiments.

As seen in Figure 8, the air side of the ribbon, which was directly exposed to the ion beam, is more seriously affected than the opposite wheel side. The changes are clearly seen in the average hyperfine magnetic field values that are significantly enhanced after ion irradiation in comparison to the as-quenched state. Both the near subsurface regions and more deep areas of the alloy are affected. The wheel side is almost intact by ion irradiation.

Nonmagnetic regions are also more sensitive to the irradiation at the air side than at the wheel side. This behaviour is documented in Figure 9 where in particular isomer shifts exhibit strong response with the rising fluence. The corresponding average quadrupole splitting is also affected. It should be noted that in deeper regions of the alloy that are scanned by CXMS from the air side there are no nonmagnetic regions detected after the irradiation with the fluence of 


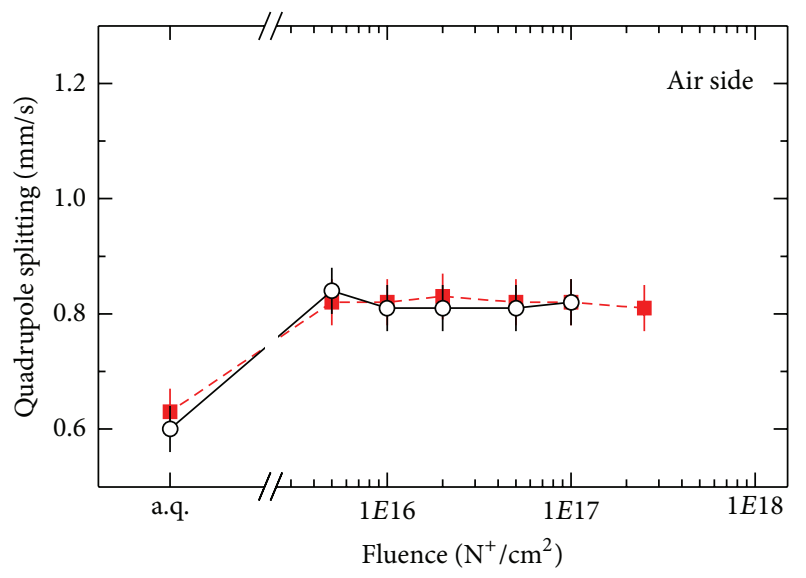

(a)

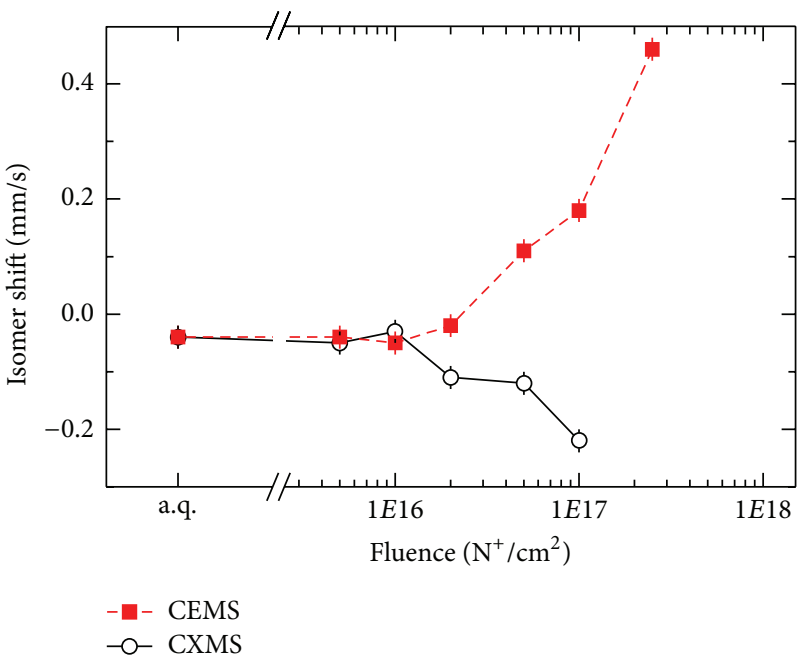

(b)

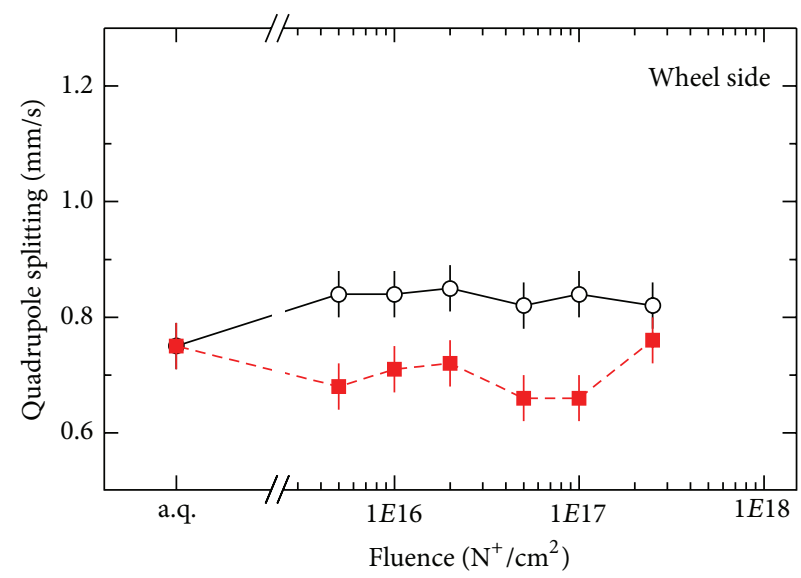

(c)

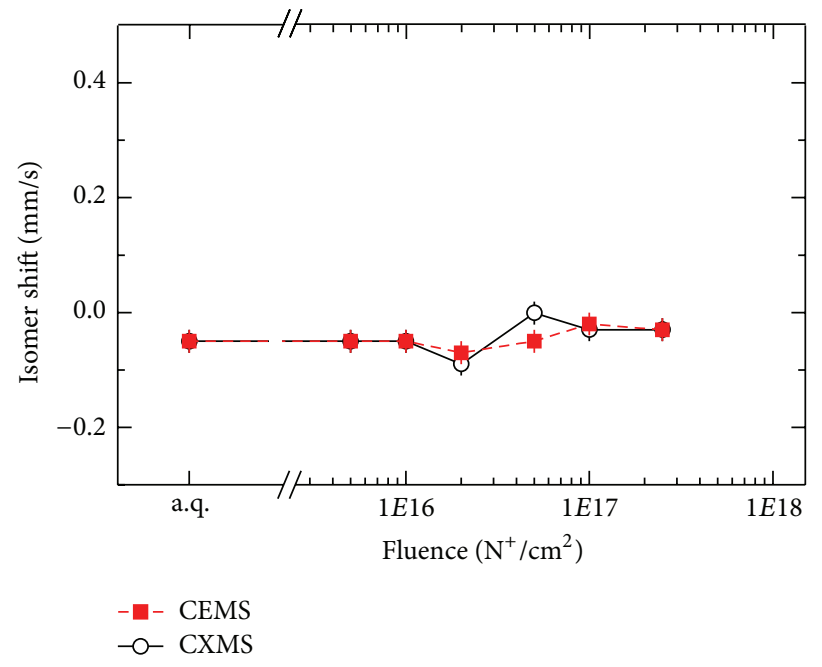

(d)

FIGURE 6: Average quadrupole splitting ( $a, c)$ and their corresponding isomer shifts $(b, d)$ obtained from the CEMS (full red squares) and CXMS (opened black circles) spectra of the ${ }^{57} \mathrm{Fe}_{75} \mathrm{Mo}_{8} \mathrm{Cu}_{1} \mathrm{~B}_{16}$ alloy that were taken from the air $(\mathrm{a}, \mathrm{b})$ and from the wheel (c, d) sides plotted against the irradiation fluence (a.q. = as-quenched). The connecting lines are only guides to the eye.

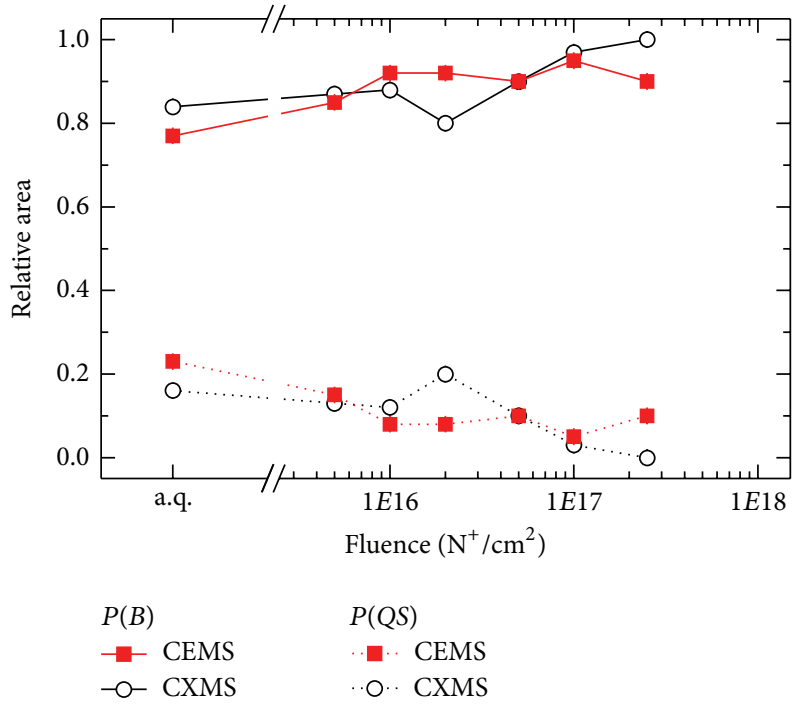

(a)

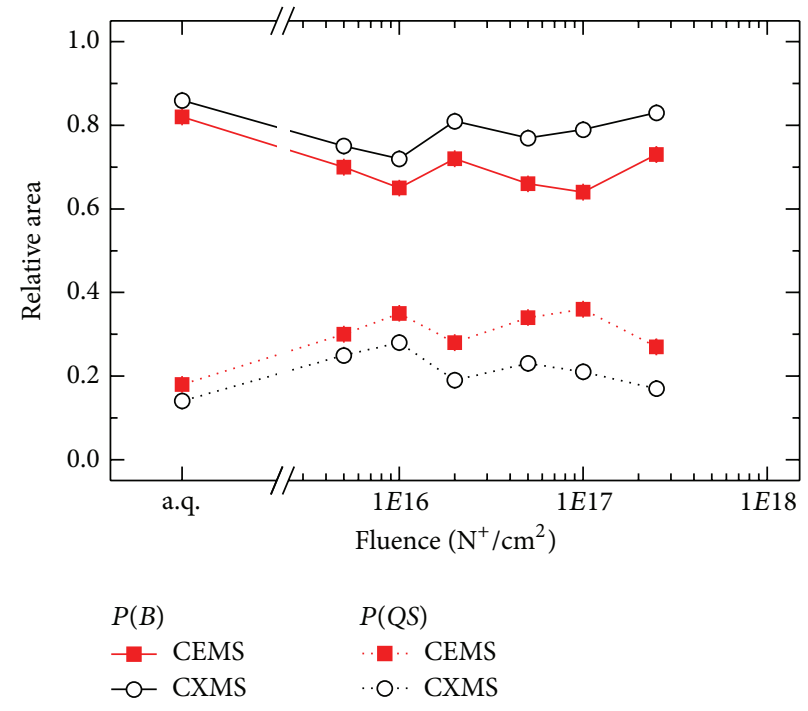

(b)

FIGURE 7: Relative area of the $P(B)$ and $P(Q S)$ spectral components as derived from CEMS (full red squares) and CXMS (opened black circles) spectra of the ${ }^{57} \mathrm{Fe}_{75} \mathrm{Mo}_{8} \mathrm{Cu}_{1} \mathrm{~B}_{16}$ alloy that were taken from the air (a) and from the wheel (b) sides plotted against the irradiation fluence (a.q. = as-quenched). The connecting lines are only guides to the eye. 


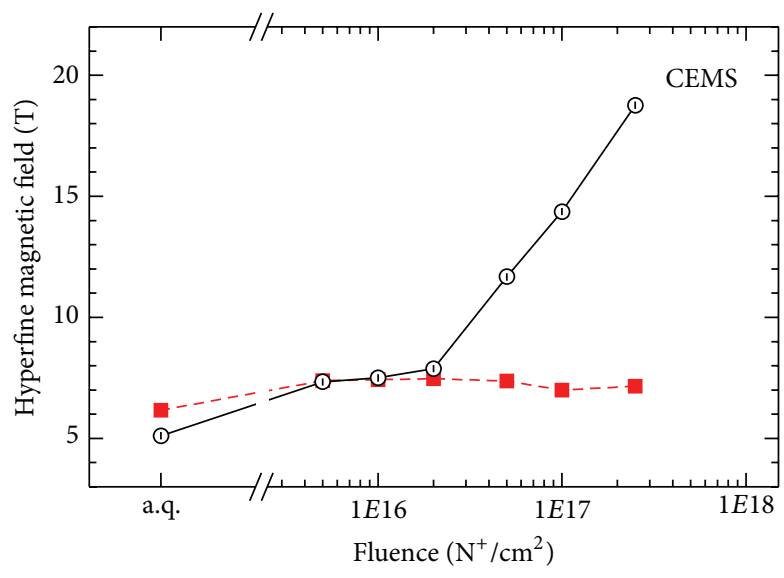

(a)

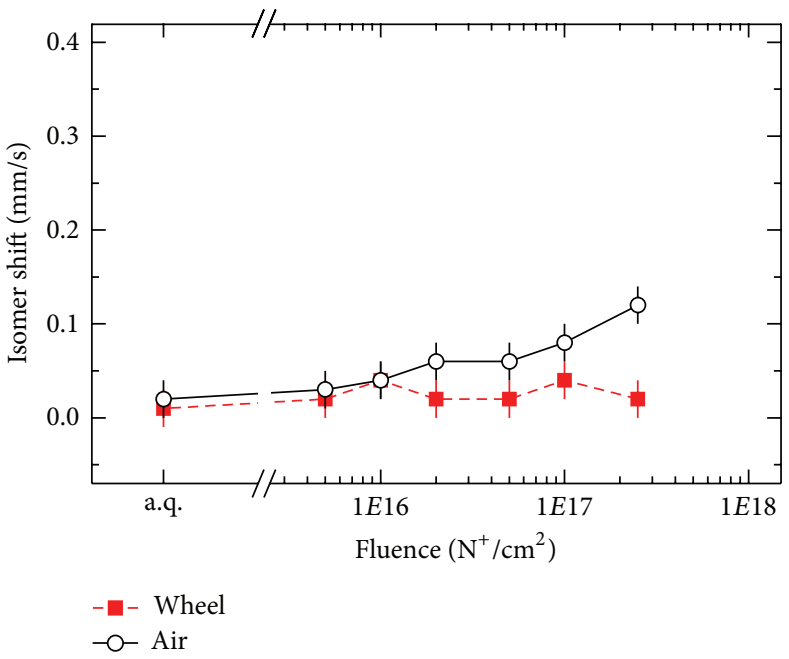

(b)

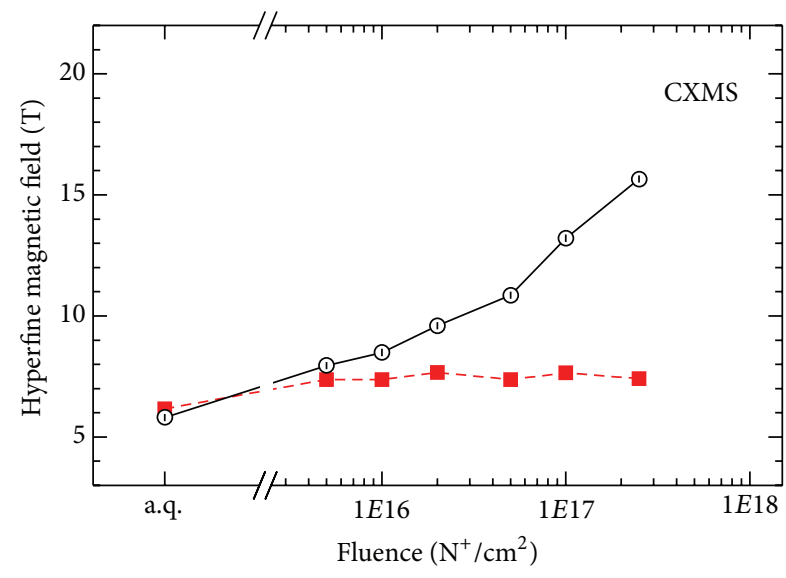

(c)

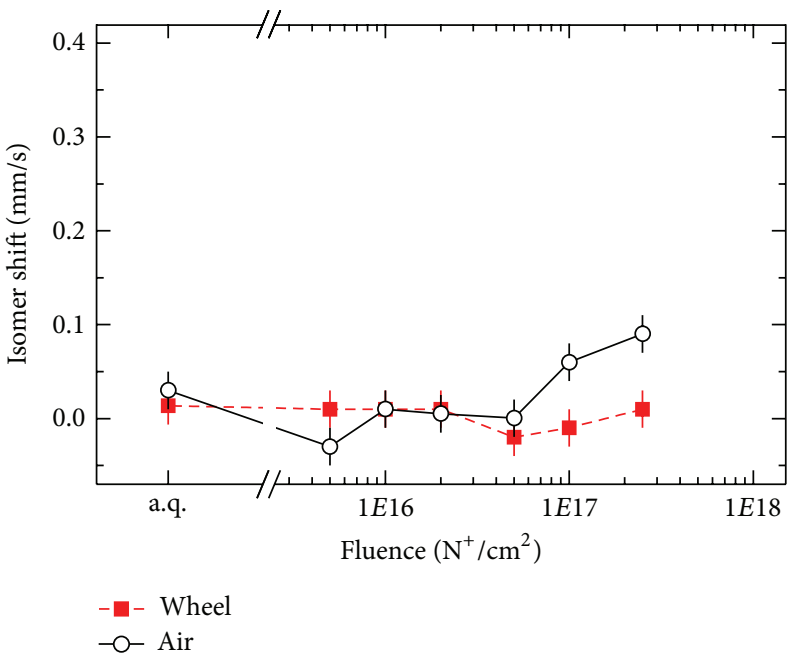

(d)

FIGURE 8: Average hyperfine magnetic field $(a, c)$ and their corresponding isomer shifts $(b, d)$ obtained from the CEMS (a, b) and CXMS (c, d) spectra of the ${ }^{57} \mathrm{Fe}_{75} \mathrm{Mo}_{8} \mathrm{Cu}_{1} \mathrm{~B}_{16}$ alloy that were taken from the air (opened black circles) and from the wheel (full red squares) sides plotted against the irradiation fluence (a.q. = as-quenched). The connecting lines are only guides to the eye.

$2.5 \times 10^{17}$ ions $/ \mathrm{cm}^{2}$ (see also Figure $7(\mathrm{a})$ ). The deviations of spectral parameters obtained from the wheel sides fall into the error margins and thus no appreciable effects of the ion bombardment were revealed.

\subsubsection{Ion Irradiation: Limited Heat Exchange between Sample} and Cooled Sample Holder. The shapes of Mössbauer spectra in Figure 1(d) or in Figure 3 at the top suggest prevailing contributions of magnetically ordered regions in the samples irradiated with high enough fluencies $\left(>5 \times 10^{16}\right.$ ions $\left./ \mathrm{cm}^{2}\right)$. Their influence upon the magnetic microstructure of the investigated alloy is mainly through high values of average hyperfine magnetic field (see Figures 5(a), 8(a), and 8(c)) rather than by their increased relative fraction (Figure $7(\mathrm{a})$ ).

Consequently, a question arises whether the observed effects are caused exclusively by radiation damage induced by the bombarding ions or should we consider also excess energy deposition which might be responsible for an increase of the sample's temperature. In order to differentiate between these two possible sources of structural modifications we have performed the irradiation with two distinct ways how the samples were attached to the sample holder. In both cases, the latter was cooled by vapours of liquid nitrogen.

In the experiments reported above in Section 3.1.1, the samples were in complete solid contact with the holder over their entire surface. Another irradiation experiments were accomplished in such a way that the ribbon-shaped samples were fastened only over small areas at their edges. Thus, the thermal contact with the cooled sample holder was rather limited and thus insufficient.

Mössbauer spectra of the ${ }^{57} \mathrm{Fe}_{75} \mathrm{Mo}_{8} \mathrm{Cu}_{1} \mathrm{~B}_{16}$ alloy that were irradiated under such conditions are shown in Figure 10. They were recorded by the CEMS technique and are presented only for selected fluencies. Even at the lowest fluence of $5 \times 10^{15}$ ions $/ \mathrm{cm}^{2}$ some nanocrystallites have evolved at the air side. Their presence is documented in Figure 10(a) by emission Mössbauer lines plotted in blue colour. According 


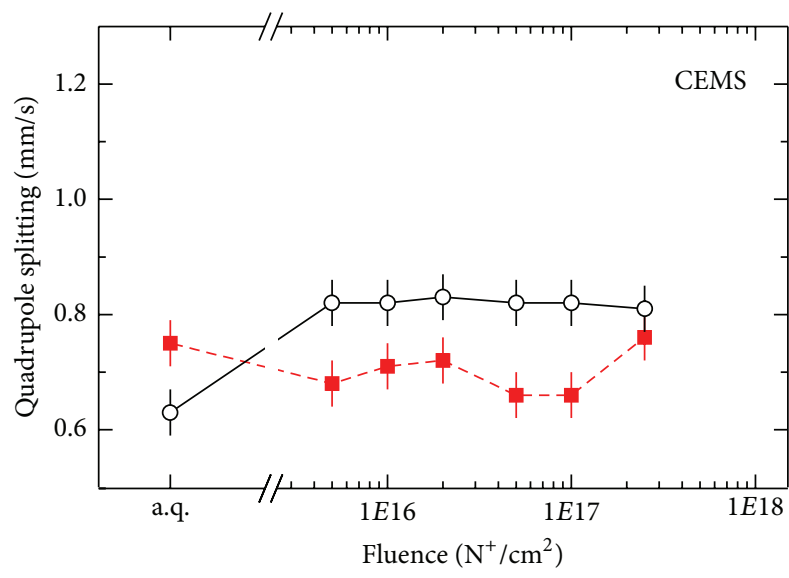

(a)

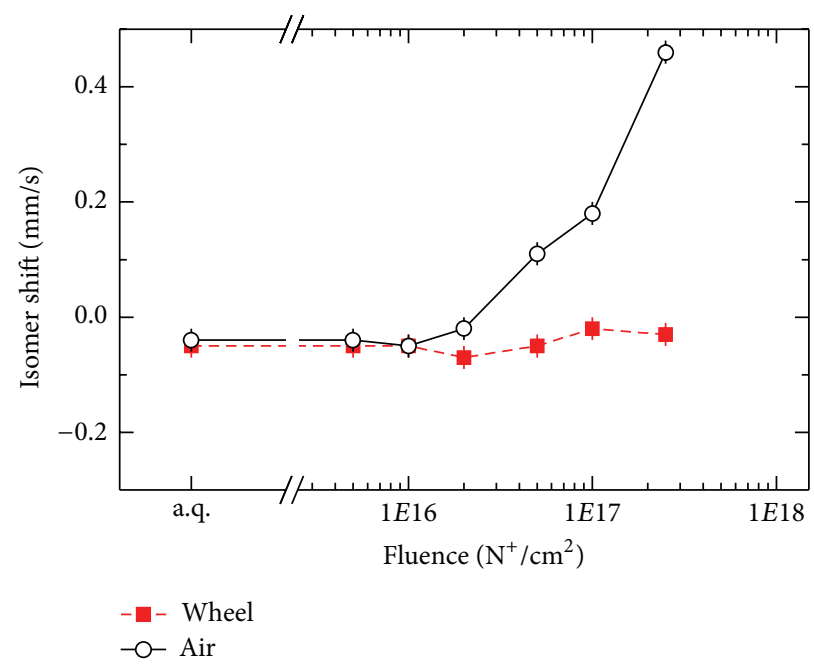

(b)

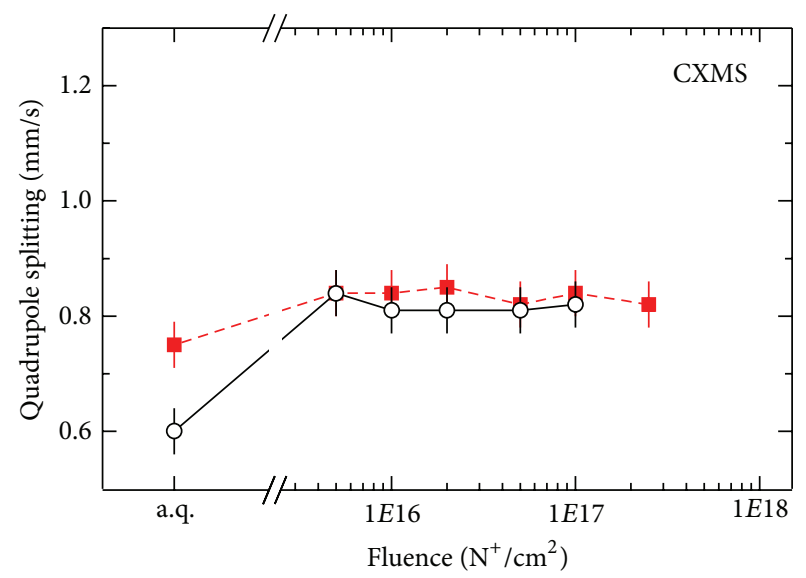

(c)

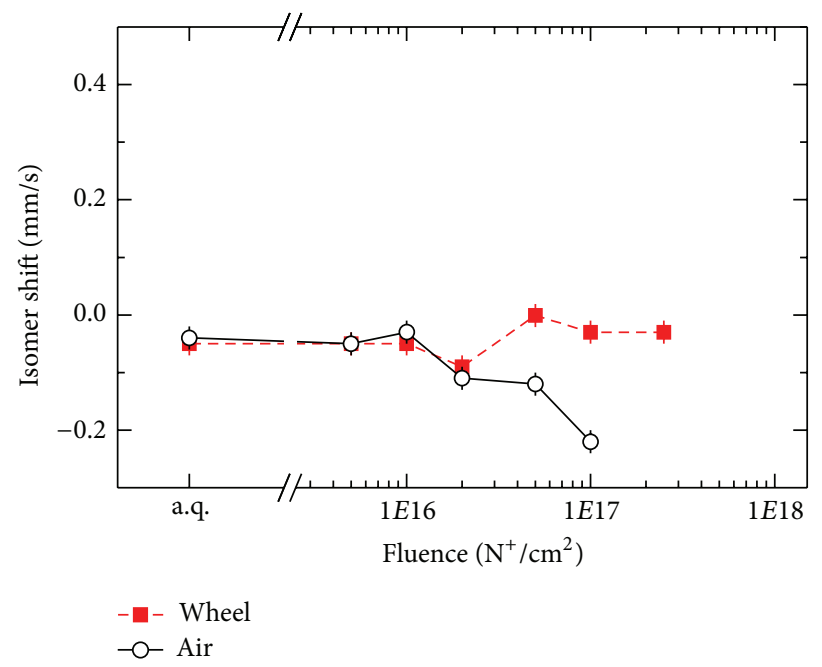

(d)

FIGURE 9: Average quadrupole splitting $(a, c)$ and their corresponding isomer shifts $(b, d)$ obtained from the CEMS (a, b) and CXMS (c, d) spectra of the ${ }^{57} \mathrm{Fe}_{75} \mathrm{Mo}_{8} \mathrm{Cu}_{1} \mathrm{~B}_{16}$ alloy that were taken from the air (opened black circles) and from the wheel (full red squares) sides plotted against the irradiation fluence (a.q. = as-quenched). The connecting lines are only guides to the eye.

to the hyperfine parameters obtained from the fits, this sextet belongs to bcc-Fe nanograins with small inclusions of nitrogen.

The amount of bcc-Fe nanocrystals rises with the ion fluence and their relative fraction is $2 \%, 4 \%$, and $12 \%$ after irradiation with $5 \times 10^{15}$ ions $/ \mathrm{cm}^{2}, 2.5 \times 10^{16}$ ions $/ \mathrm{cm}^{2}$, and 2.5 $\times 10^{17}$ ions $/ \mathrm{cm}^{2}$, correspondingly. After the highest fluence, additional spectral lines appear in Figure 10(c) which are plotted in green colour. They belong to two sextets of magnetite $\left(\mathrm{Fe}_{3} \mathrm{O}_{4}\right)$ which has formed in the subsurface layers. The latter are found also on the wheel side as seen in Figures 10(d)-10(e). However, no traces of bcc-Fe were identified, here. Screening in more deep regions of the samples by CXMS has led to similar results (not shown).

The nanocrystallization which has occurred during the ion irradiation was triggered by elevated temperature of the samples as a result of limited thermal contact with the cooled sample holder. It is also noteworthy that the shapes of CEMS spectra taken from the air side notably differ from those in Figure 3 for the same fluencies. Presence of magnetically active regions that are characterized by sextets of Mössbauer lines is more clearly visible. We assume that they belong to iron nitrides the formation of which was initiated by the combined effect of radiation damage and elevated temperature.

3.1.3. Thermal Annealing, Formation of Nanocrystalline Alloy. In the above sections we have discussed the effects of ion irradiation with and without sufficient heat exchange between the irradiated sample and a cooled sample holder. We have demonstrated notable differences upon structural modifications of the investigated alloys caused by these two ways of irradiation. Still, the effect of elevated temperature alone is difficult to assess from the presented data because the degree of limited heat exchange cannot be directly measured due to technical difficulties. In addition, the simultaneous impact of radiation damage and elevated temperature most 


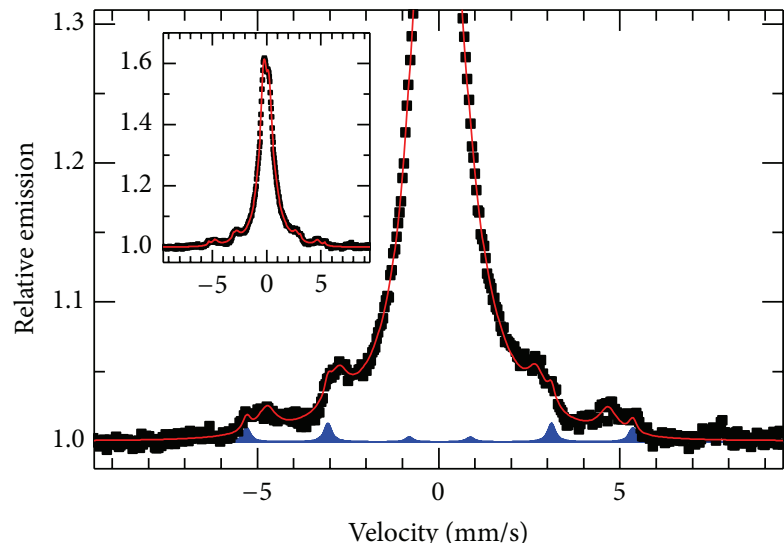

(a)

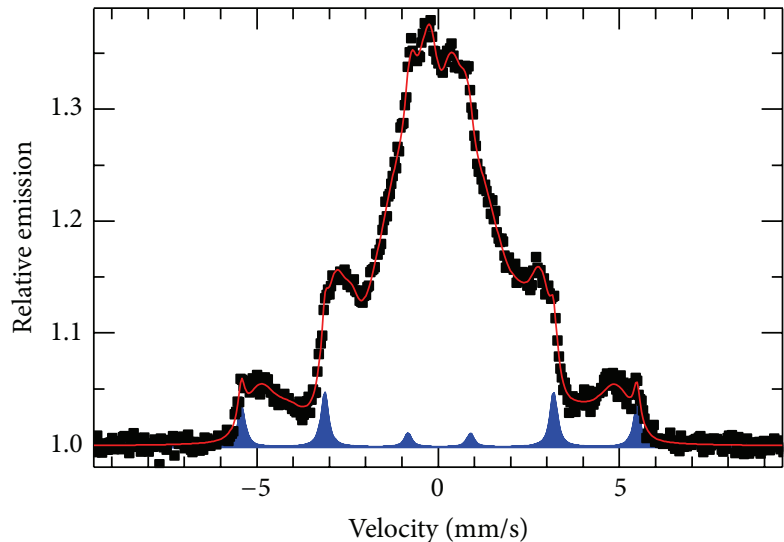

(b)

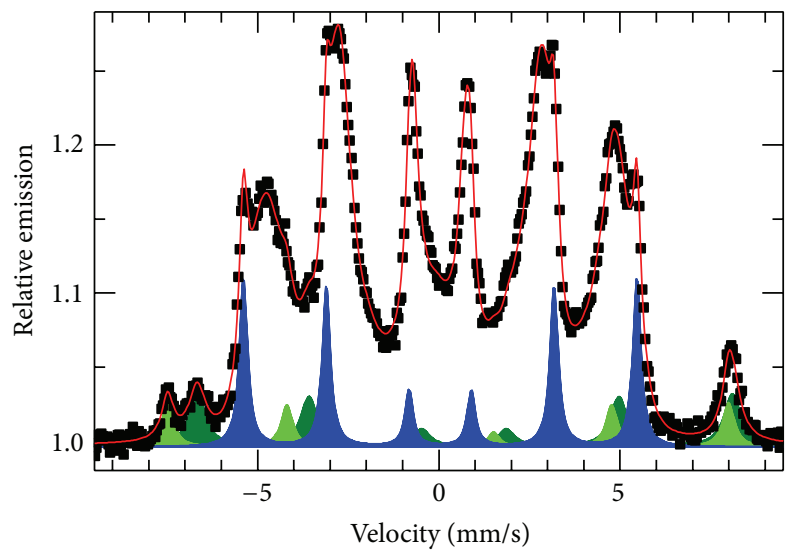

(c)

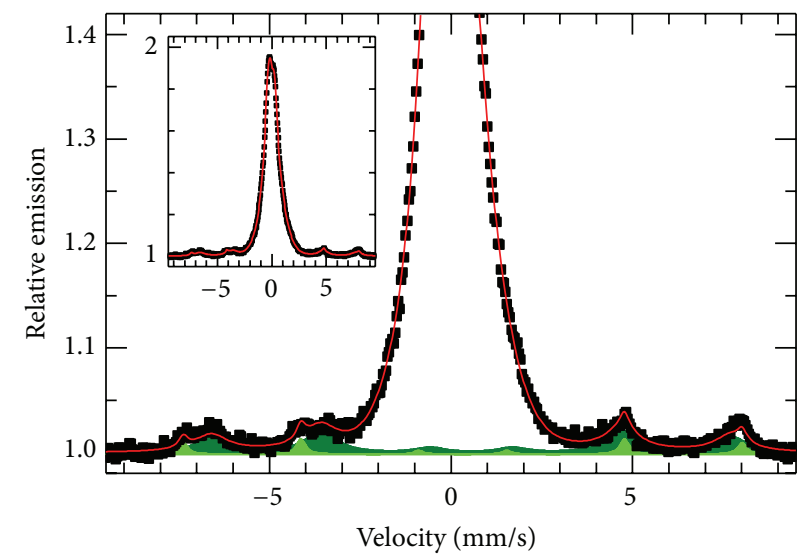

(d)

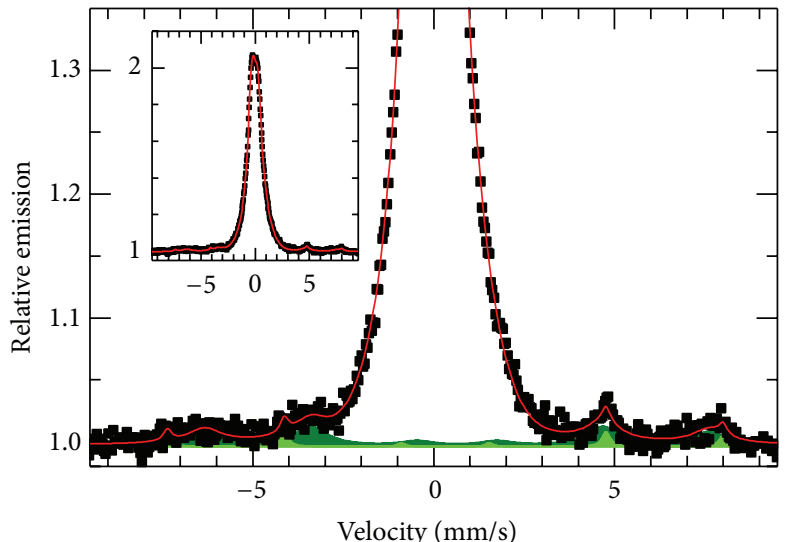

(e)

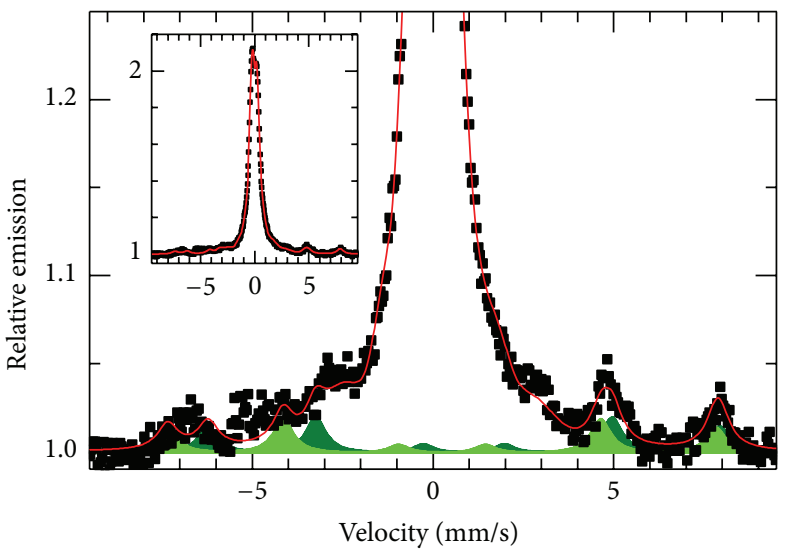

(f)

FIGURE 10: CEMS Mössbauer spectra of the ${ }^{57} \mathrm{Fe}_{75} \mathrm{Mo}_{8} \mathrm{Cu}_{1} \mathrm{~B}_{16}$ alloy after irradiation with $5 \times 10^{15}$ ions $/ \mathrm{cm}^{2}(\mathrm{a}, \mathrm{d}), 2.5 \times 10^{16}$ ions $/ \mathrm{cm}^{2}(\mathrm{~b}, \mathrm{e})$, and $2.5 \times 10^{17}$ ions $/ \mathrm{cm}^{2}(\mathrm{c}, \mathrm{f})$ as obtained from the air $(\mathrm{a}, \mathrm{b}$, and $\mathrm{c}$ ) and wheel (d, e, and f) sides of the ribbons with limited thermal contact with the sample holder. The insets show the whole spectra. See text for the description of the coloured spectral components.

probably exhibits some synergy. Having that in mind, we have prepared a set of samples from the original as-quenched ${ }^{57} \mathrm{Fe}_{75} \mathrm{Mo}_{8} \mathrm{Cu}_{1} \mathrm{~B}_{16}$ alloy that were subjected to 30 min heat treatments in a vacuum without ion irradiation. The applied annealing temperatures were chosen close to the temperature of the onset of crystallization for this system which was determined by DSC $\left(T_{x 1}=735 \mathrm{~K}\right)$.

During the thermal treatment, the originally amorphous MGs are partially crystallized and nanocrystalline grains are produced. They are identified by the help of the hyperfine 


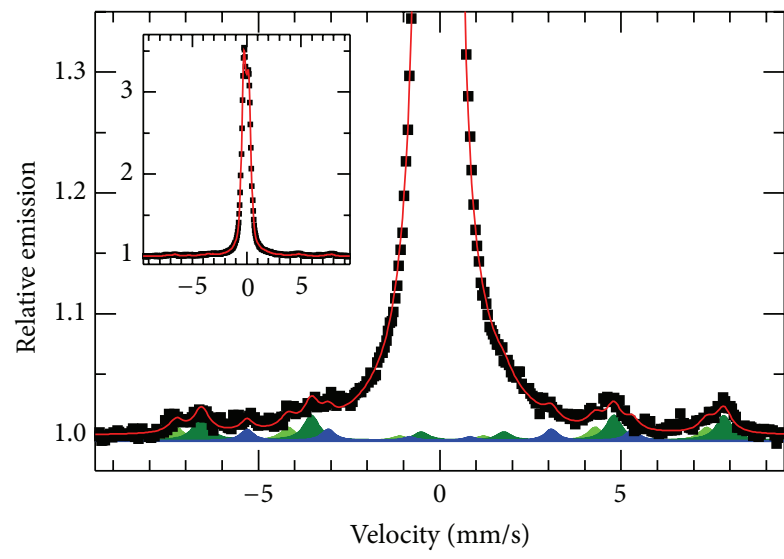

(a)

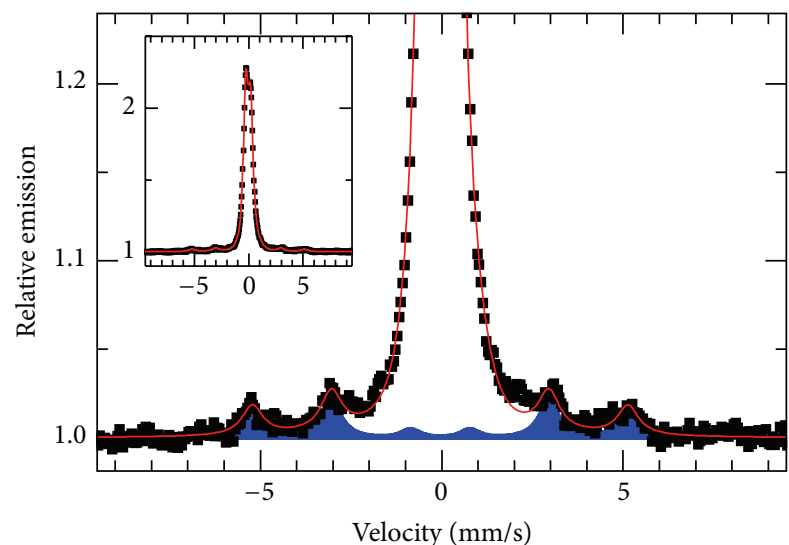

(b)

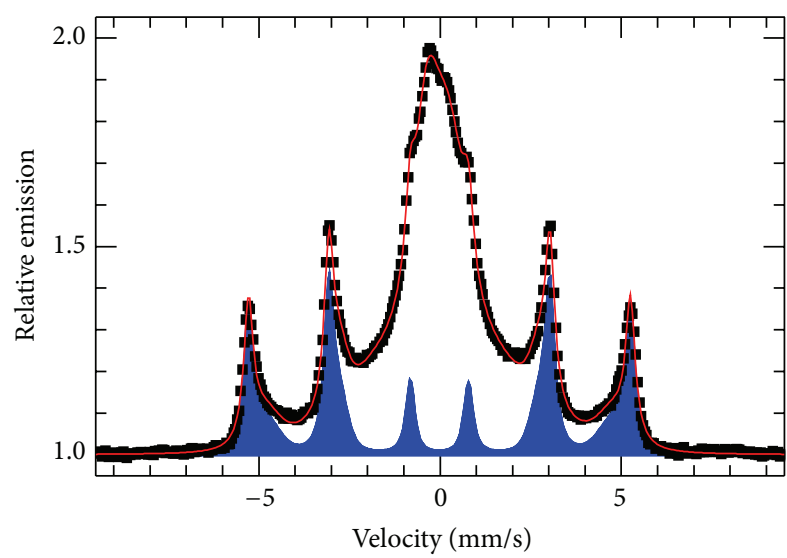

(c)

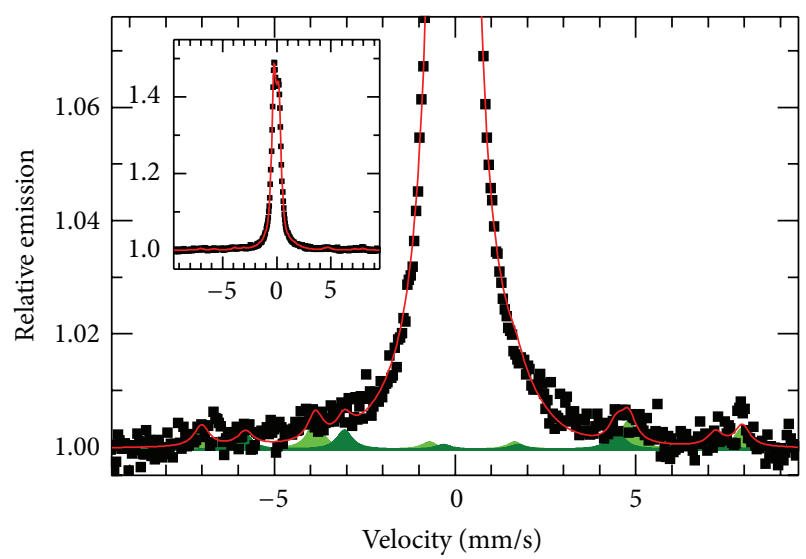

(d)

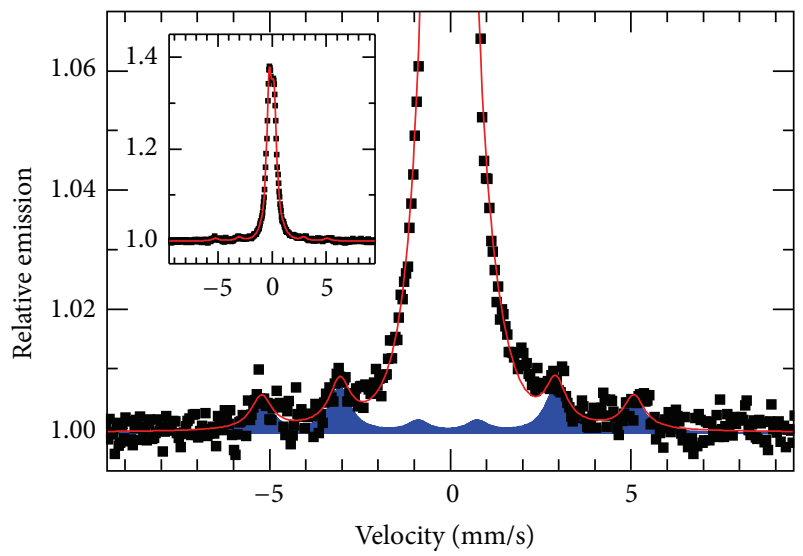

(e)

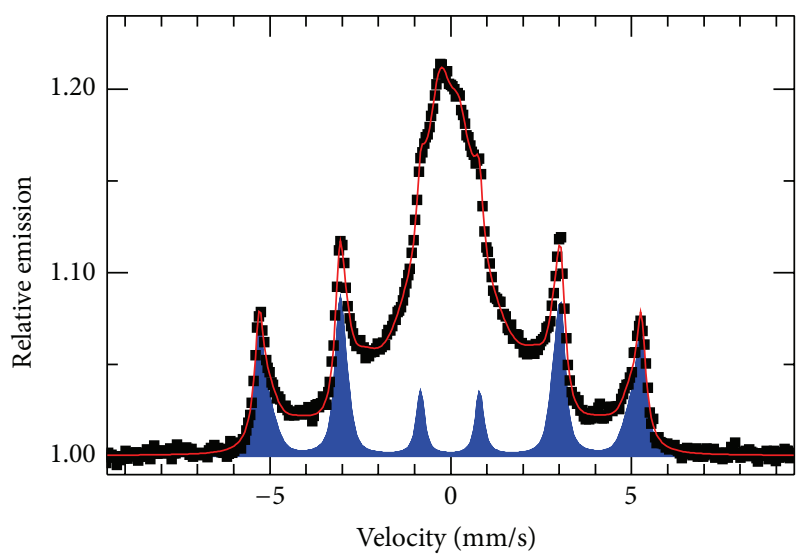

(f)

FIGURE 11: CEMS (a, b, and c) and CXMS (d, e, and f) spectra of the ${ }^{57} \mathrm{Fe}_{75} \mathrm{Mo}_{8} \mathrm{Cu}_{1} \mathrm{~B}_{16}$ alloy that were taken from the air side after annealing at $643 \mathrm{~K}(\mathrm{a}, \mathrm{d}), 723 \mathrm{~K}(\mathrm{~b}, \mathrm{e})$, and $783 \mathrm{~K}(\mathrm{c}, \mathrm{f})$. The insets show the whole spectra. See text for the description of coloured spectral components.

spectral parameters including hyperfine magnetic field and isomer shift. For this MG, the emerging narrow spectral lines are positioned well beyond the central broad signal and can be thus easily recognized as demonstrated in Figure 11 where CEMS and CXMS spectra obtained from the air side of the annealed samples are displayed. The sextet of bcc-Fe and/or the two sextets of $\mathrm{Fe}_{3} \mathrm{O}_{4}$ are plotted in blue and green colours, respectively.

The relative fraction of bcc-Fe increases with rising temperature of annealing from $\sim 1 \%$ for $643 \mathrm{~K}$, to $\sim 6 \%$ for $723 \mathrm{~K}$, and $\sim 31 \%$ for $783 \mathrm{~K}$ as derived from CEMS, that is, near subsurface regions. In more deep areas of the samples, 


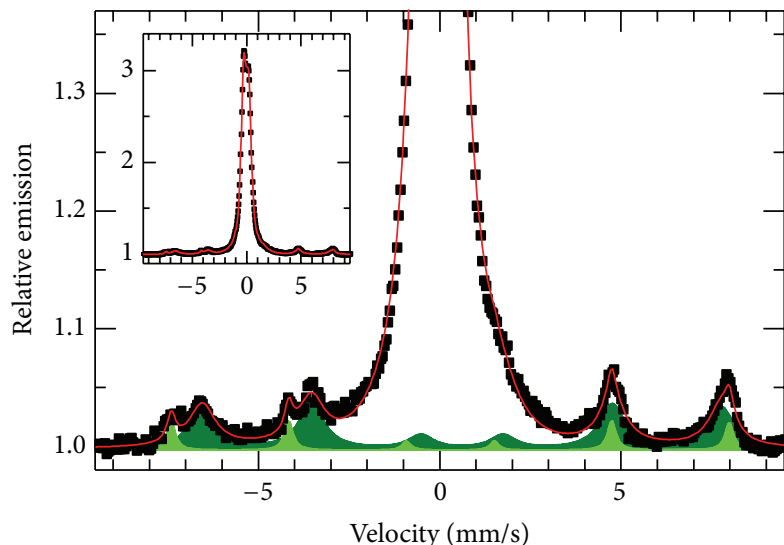

(a)

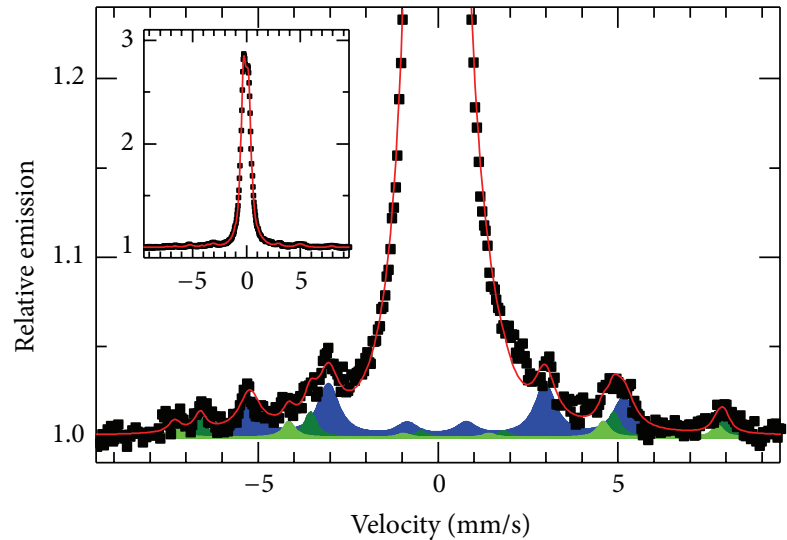

(b)

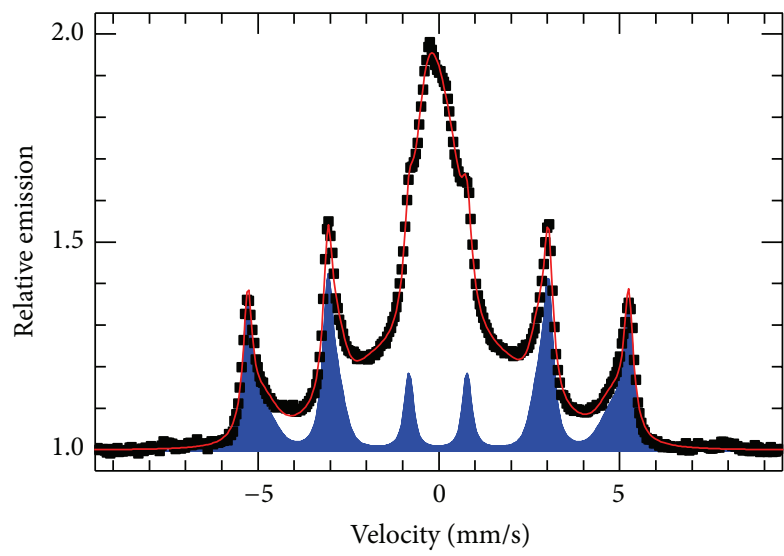

(c)

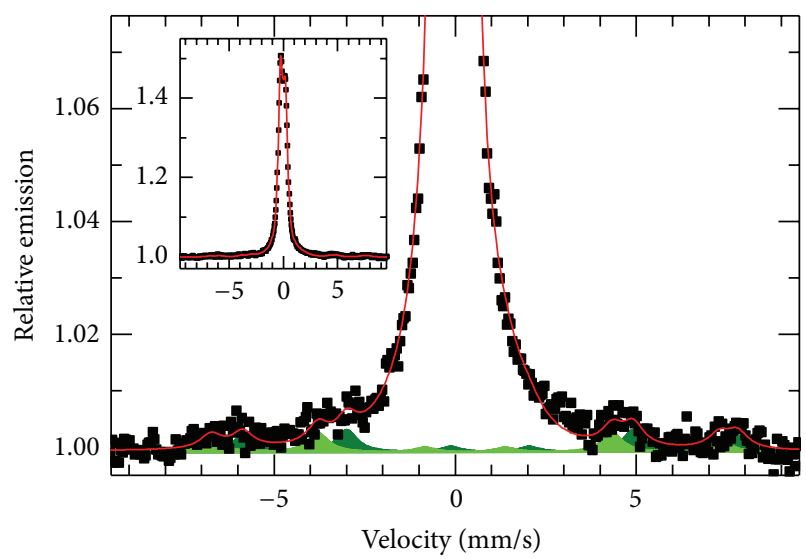

(d)

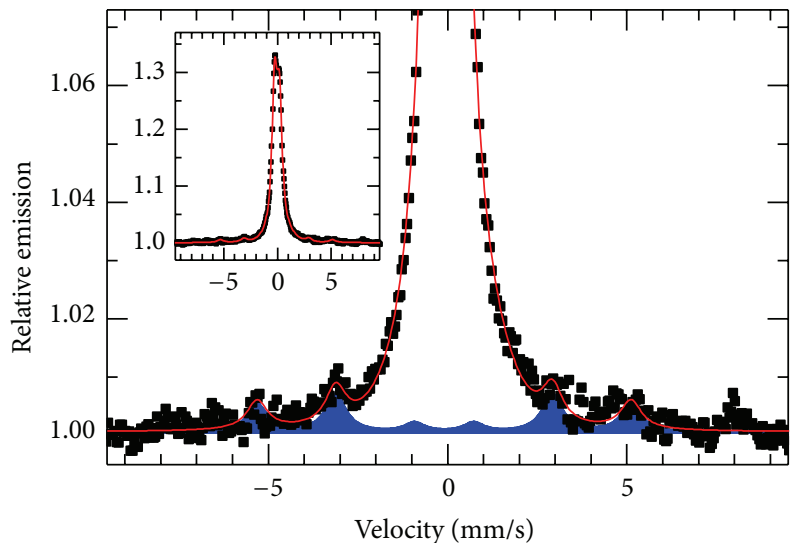

(e)

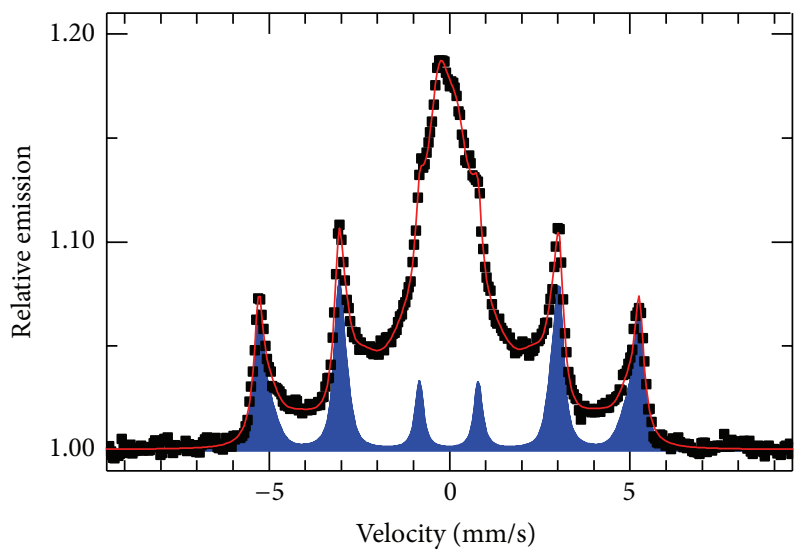

(f)

FIGURE 12: CEMS (a, b, and c) and CXMS (d, e, and f) spectra of the ${ }^{57} \mathrm{Fe}_{75} \mathrm{Mo}_{8} \mathrm{Cu}_{1} \mathrm{~B}_{16}$ alloy that were taken from the wheel side after annealing at $643 \mathrm{~K}(\mathrm{a}, \mathrm{d}), 723 \mathrm{~K}(\mathrm{~b}, \mathrm{e})$, and $783 \mathrm{~K}(\mathrm{c}, \mathrm{f})$. The insets show the whole spectra. See text for the description of coloured spectral components.

CXMS provided almost zero bcc-Fe for $643 \mathrm{~K}, \sim 7 \%$ for $723 \mathrm{~K}$, and $\sim 23 \%$ for $783 \mathrm{~K}$ annealing. It should be noted that especially for high enough annealing temperature the amount of nanocrystals found in the sample's depth is already quite close to that at the near surface regions. So, the production of nanocrystalline phases is distributed over the entire bulk of the samples with enhanced appearance towards its surfaces.
This is quite different observation from that in the irradiated alloys where production of bcc-Fe nanograins is confined to the near surface regions. Moreover, they were found only at the air sides of the irradiated alloys through which the bombarding ions have penetrated into the ribbons.

The situation for the wheel side is demonstrated in Figure 12. Contrary to the air side, the amount of $\mathrm{Fe}_{3} \mathrm{O}_{4}$ 
is slightly higher for the $643 \mathrm{~K}$ annealing ( $7 \%$ and $~ 5 \%$ derived from CEMS and CXMS, resp.) and about $2 \%$ are found also in the near surface regions (CEMS) after annealing at $723 \mathrm{~K}$. No traces of bcc-Fe can be seen at the wheel side after annealing at $643 \mathrm{~K}$. Elevating the temperature to 723 and $783 \mathrm{~K}$ has produced $\sim 5 \%(\sim 6 \%)$ and $\sim 31 \%(\sim 25 \%)$ of bcc-Fe, respectively, in the CEMS (CXMS) spectra. As in the previous case, the spectral components associated with bccFe and $\mathrm{Fe}_{3} \mathrm{O}_{4}$ are plotted in Figure 12 in blue and green colour, respectively.

Looking at the shapes as well as relative amounts of nanocrystalline grains that were detected on the air and wheel sides in various depths under the surface we can conclude that the newly emerged nanocrystals are quite homogeneously dispersed over the inspected regions. The spectra are different from those of the irradiated samples where no traces of nanocrystals were revealed as seen in Figures 3 and 4 (with one exception at the $2.5 \times 10^{17}$ ions $/ \mathrm{cm}^{2}$ fluence on the air side). During the irradiation with not proper thermal contact between the sample and the cooled sample holder, partial crystallization is anticipated due to a temperature increase. Indeed, formation of bcc-Fe phase was unveiled but only at the air side of the ribbons (Figures 10(a)-10(c)). No bcc-Fe nanocrystals was detected at the opposite wheel side (Figures $10(\mathrm{~d})-10(\mathrm{f}))$. It should be noted bcc-Fe phase is the principal product of crystallization in NANOPERM-type alloys [33]. Thus, even though the temperature was presumably increased during ion irradiation with insufficient heat exchange the overheating has occurred only locally and has not affected the entire sample.

\subsection{Magnetic Measurements}

3.2.1. Ion Irradiation. In order to inspect the impact of ion irradiation upon the whole bulk of the investigated alloys we have measured their magnetic characteristics comprising temperature evolution of magnetization $M(T)$ under zero field cooling (ZFC) and field cooling (FC) conditions, Curie temperature $T_{C}$, and hysteresis loops. The results presented below were obtained from the samples which were during the irradiation firmly attached to a cooled sample holder. Thus, they correspond to the Mössbauer spectrometry measurements provided in Section 3.1.1.

Temperature dependencies of ZFC magnetizations in Figure 13 were measured with a constant magnetizing flux density $\mu_{0} H=0.1 \mathrm{~T}$. The magnetization decreases over the whole temperature range for all investigated samples like in ferromagnetic materials. An inflection in $M(T)$ curves is observed close to the ferromagnetic Curie temperature $T_{C}$ for all samples. At higher temperatures, that is, above $T_{C}$ the magnetization decreases and a paramagnetic behaviour is observed. Moreover, the magnetizations increase at low temperature with rising ion fluencies. This implies an effect of radiation damage towards formation of higher contributions of magnetically active regions in the irradiated alloys. This assumption correlates well with the finding of Mössbauer spectrometry.

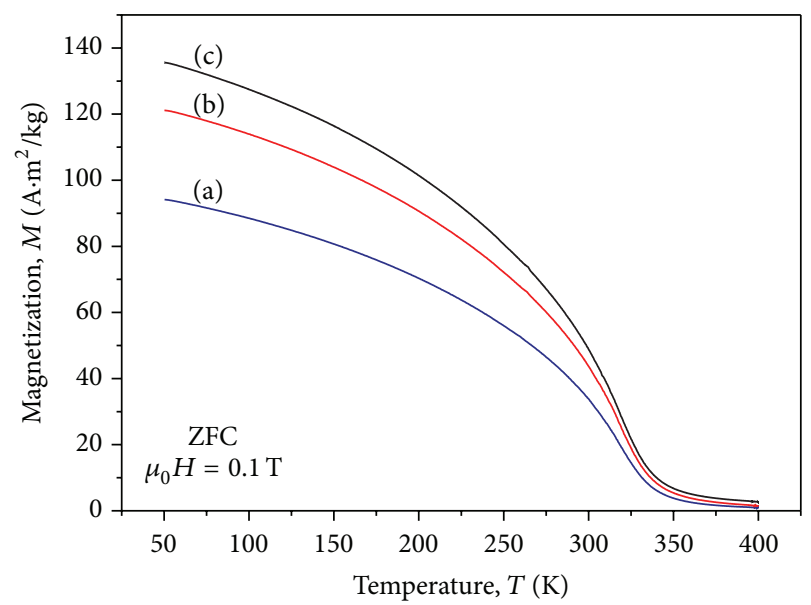

FIGURE 13: Zero field cooling magnetization versus temperature for the ${ }^{57} \mathrm{Fe}_{75} \mathrm{Mo}_{8} \mathrm{Cu}_{1} \mathrm{~B}_{16}$ alloy after irradiation with $5 \times 10^{15} \mathrm{ions} / \mathrm{cm}^{2}$ (a), $2 \times 10^{16}$ ions $/ \mathrm{cm}^{2}$ (b), and $2.5 \times 10^{17}$ ions $/ \mathrm{cm}^{2}$ (c) measured in external magnetic field of $\mu_{0} H=0.1 \mathrm{~T}$.

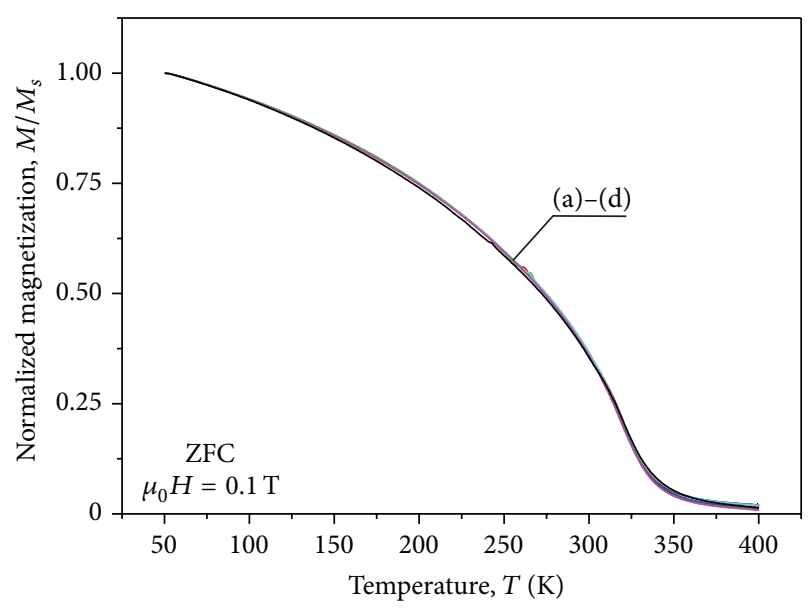

FIGURE 14: The temperature dependence of normalized zero field cooling magnetization $M(T) / M_{\max }$ measured in external magnetic field of $0.1 \mathrm{~T}$ for the ${ }^{57} \mathrm{Fe}_{75} \mathrm{Mo}_{8} \mathrm{Cu}_{1} \mathrm{~B}_{16}$ alloy after irradiation with $5 \times$ $10^{15}$ ions $/ \mathrm{cm}^{2}$ (a), $2 \times 10^{16}$ ions $/ \mathrm{cm}^{2}$ (b), and $2.5 \times 10^{17}$ ions $/ \mathrm{cm}^{2}$ (c), and the as-quenched nonirradiated sample $(\mathrm{d})$.

For the sake of mutual comparison, the ZFC magnetizations curves from Figure 13 were normalized according to their maximum values at the lowest temperature. The results are demonstrated in Figure 14. As it can be seen, there are no obvious deviations observed in the temperature evolution among the thermomagnetic lines. Normalized magnetization of the as-quenched, that is, nonirradiated alloy, was also included. Consequently, no changes in $T_{C}$ of the investigated materials are expected. The observed increased magnetization values in Figure 13 can be thus assigned only to structural rearrangement caused by the ion irradiation.

Curie temperature $T_{C}$ of the investigated alloys was determined by two methods. One of them uses the $M(T)$ 


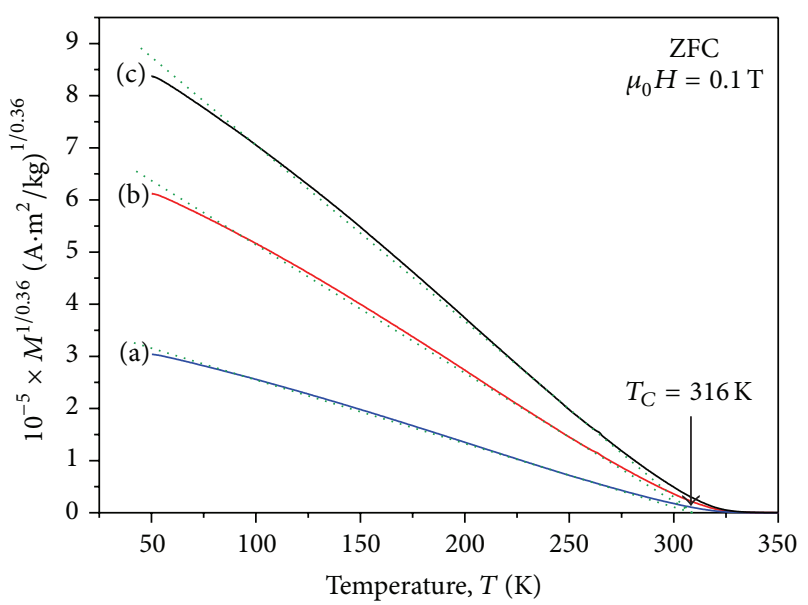

FIGURE 15: Zero field cooling $M^{1 / \beta}$ as a function of temperature $(\beta=0.36)$ for the ${ }^{57} \mathrm{Fe}_{75} \mathrm{Mo}_{8} \mathrm{Cu}_{1} \mathrm{~B}_{16}$ alloy after irradiation with 5 $\times 10^{15}$ ions $/ \mathrm{cm}^{2}$ (a), $2 \times 10^{16}$ ions $/ \mathrm{cm}^{2}$ (b), and $2.5 \times 10^{17} \mathrm{ions} / \mathrm{cm}^{2}$ (c) in the ferromagnetic region, measured in external magnetic field $\mu_{0} H=0.1 \mathrm{~T}$. $T_{C}=316 \mathrm{~K}$ represents the Curie temperature of the investigated samples.

curves recorded at constant magnetizing flux density $\mu_{0} H=$ $0.1 \mathrm{~T}$ according to the relation:

$$
M(T) \propto\left(1-\frac{T}{T_{C}}\right)^{\beta},
$$

where $M(T)$ is magnetization at temperature of measurement $T, T_{C}$ is Curie temperature, $\beta$ is critical exponent $(\beta=0.36$ for Heisenberg's ferromagnets). Results of the $T_{C}$ determination according to this analysis are shown in Figure 15. The $M^{1 / \beta}$ curves $(\beta=0.36)$ were fitted with linear lines which have provided $T_{C}=316 \mathrm{~K}$ for all irradiated samples. A small increase of $T_{C}$ after ion irradiation is observed in comparison to the nonirradiated as-quenched alloy $\left(T_{C}=313 \mathrm{~K}[32]\right)$. Nevertheless, the observed change falls nearly into the error range.

Another method of $T_{C}$ determination is related to finding inflection points on the $M(T)$ curves. They correspond to minima of their derivatives $d M(T) / d T$ that are shown in Figure 16. The first derivative of magnetizations recorded with a magnetizing flux density of $\mu_{0} H=5 \mathrm{mT}$ versus temperature is displayed. From all curves, $T_{C}=316 \mathrm{~K}$ was determined and the Curie points do not change with the increasing fluence. Moreover, it can be concluded that ion irradiation changes neither average distances nor exchange interactions among Fe atoms.

Temperature dependence of inverse magnetization $M^{-1}$ in paramagnetic regions measured with a magnetic flux density of $0.1 \mathrm{~T}$ is plotted for the irradiated samples in Figure 17. It is seen that the temperature dependencies of $M^{-1}$ are in good agreement with the Curie-Weiss law which describes the magnetic susceptibility of ferromagnetic materials in paramagnetic regions above the ferromagnetic Curie temperature:

$$
\chi=\frac{M}{H}=\frac{C}{T-T_{C p a r}},
$$

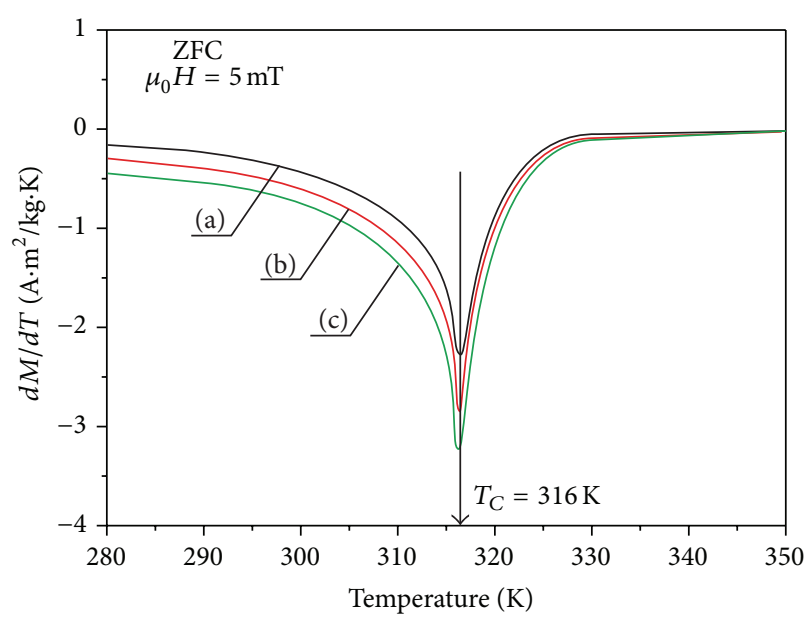

FIGURE 16: Derivative $d M / d T$ plotted versus temperature for the ${ }^{57} \mathrm{Fe}_{75} \mathrm{Mo}_{8} \mathrm{Cu}_{1} \mathrm{~B}_{16}$ alloy after irradiation with $5 \times 10^{15}$ ions $/ \mathrm{cm}^{2}$ (a), $2 \times 10^{16}$ ions $/ \mathrm{cm}^{2}(\mathrm{~b})$, and $2.5 \times 10^{17}$ ions $/ \mathrm{cm}^{2}$ (c).

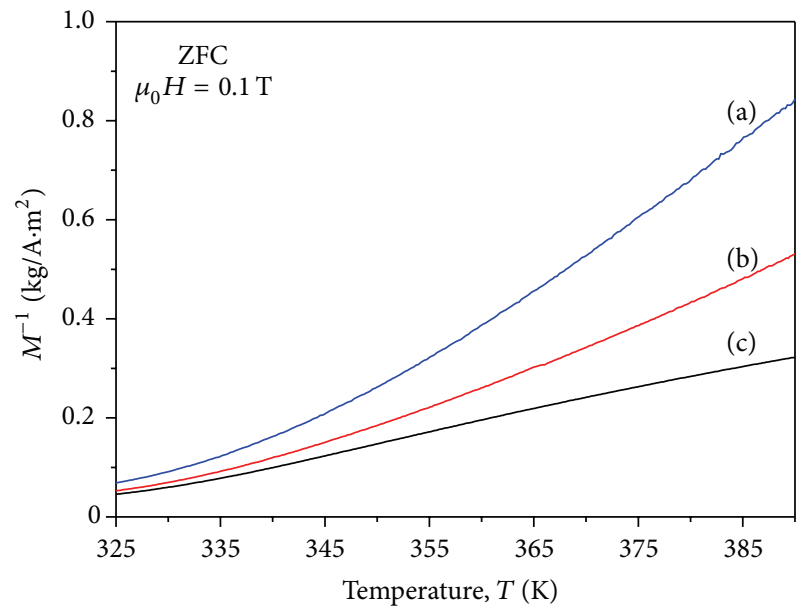

FIgURE 17: Zero field cooling $M^{-1}$ plotted versus temperature for the ${ }^{57} \mathrm{Fe}_{75} \mathrm{Mo}_{8} \mathrm{Cu}_{1} \mathrm{~B}_{16}$ alloy after irradiation with $5 \times 10^{15}$ ions $/ \mathrm{cm}^{2}$ (a), 2 $\times 10^{16}$ ions $/ \mathrm{cm}^{2}(\mathrm{~b})$, and $2.5 \times 10^{17}$ ions $/ \mathrm{cm}^{2}$ (c) in the paramagnetic region measured in external magnetic field $\mu_{0} H=0.1 \mathrm{~T}$.

where $M$ is magnetization, $H$ is magnetizing field, $C$ is constant, $T$ is temperature, and $T_{C p a r}$ is paramagnetic Curie temperature. It is noteworthy that the magnetization above the ferromagnetic Curie temperature decreases with increasing fluence.

Paramagnetic Curie temperature $T_{\text {Cpar }}$ was determined from numerical analysis of the data presented in Figure 17 according to (2). The obtained $T_{C \text { par }}$ equal $334 \mathrm{~K}, 329 \mathrm{~K}$, and $314 \mathrm{~K}$ for the ${ }^{57} \mathrm{Fe}_{75} \mathrm{Mo}_{8} \mathrm{Cu}_{1} \mathrm{~B}_{16}$ alloy after irradiation with 5 $\times 10^{15}$ ions $/ \mathrm{cm}^{2}, 2 \times 10^{16}$ ions $/ \mathrm{cm}^{2}$, and $2.5 \times 10^{17}$ ions $/ \mathrm{cm}^{2}$, respectively.

Temperature dependencies of magnetization for zero field cooling (ZFC) and field cooling (FC) experiments performed in different external magnetic fields upon the ${ }^{57} \mathrm{Fe}_{75} \mathrm{Mo}_{8} \mathrm{Cu}_{1} \mathrm{~B}_{16}$ alloy after irradiation with $5 \times$ $10^{15}$ ions $/ \mathrm{cm}^{2}$ are shown in Figure 18. 


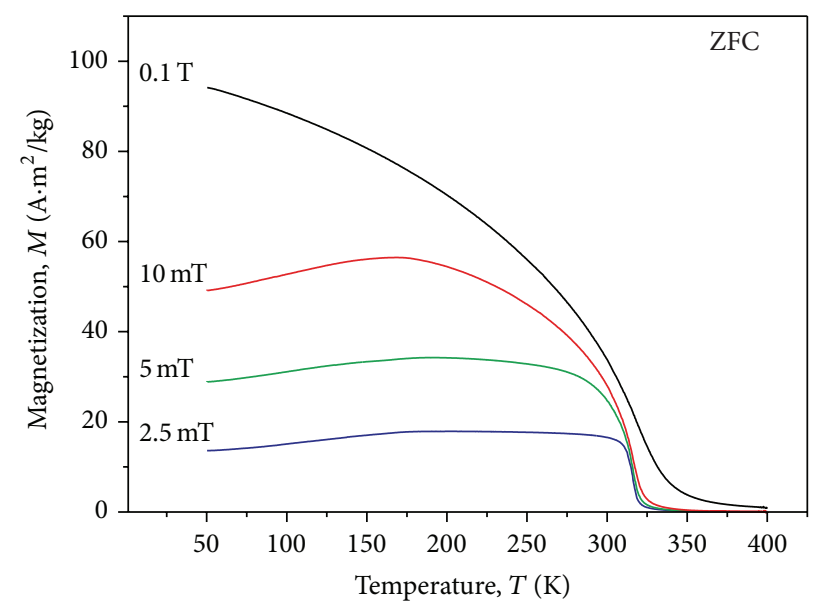

(a)

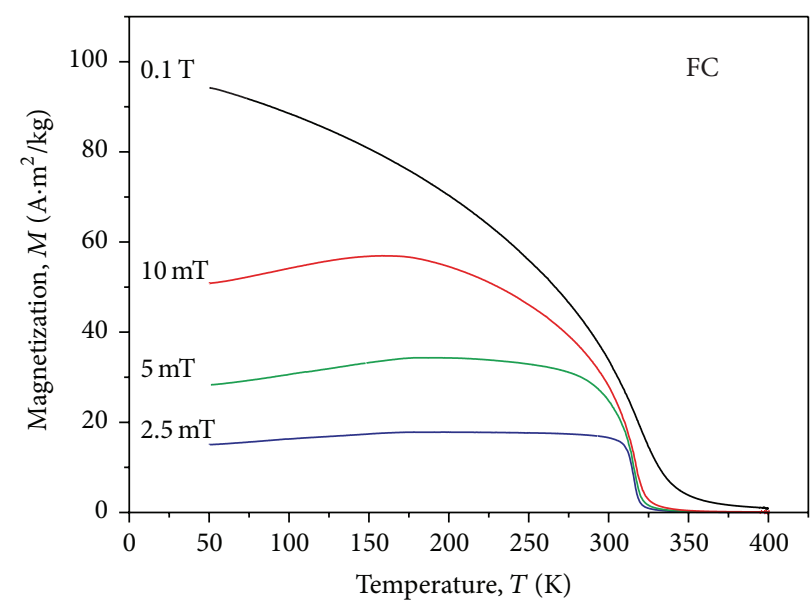

(b)

Figure 18: Zero field cooling (a) and field cooling (b) magnetizations plotted versus temperature for the ${ }^{57} \mathrm{Fe}_{75} \mathrm{Mo}_{8} \mathrm{Cu}_{1} \mathrm{~B}_{16}$ alloy after irradiation with $5 \times 10^{15}$ ions $/ \mathrm{cm}^{2}$ measured in the indicated external magnetic fields.

Increase of the magnetization is observed with growing magnetic flux density for both ZFC and FC samples irradiated with the fluence of $5 \times 10^{15}$ ions $/ \mathrm{cm}^{2}$. For lower external magnetic fields $\mu_{0} H \leq 10 \mathrm{mT}$, the magnetization slightly increases with temperature to its maximum and then suddenly drops down at the vicinity of $T_{C}$. The escalating of magnetization can be described by taking different temperature dependence of magnetization and that of anisotropy into account. The observed dependencies imply that the magnetization decreases more slowly with temperature than the anisotropy constant does. In high enough external magnetic field $\left(\mu_{0} H=0.1 \mathrm{~T}\right)$ a monotonous decrease of magnetization with temperature is observed. It is worth noting that the ZFC and FC $M(T)$ dependencies are almost identical. The same behaviour of magnetization was also observed for the alloys irradiated with $2 \times 10^{16}$ ions $/ \mathrm{cm}^{2}$ and $2.5 \times 10^{17}$ ions $/ \mathrm{cm}^{2}$ (not shown).

Comparison of the behaviour of ZFC magnetizations recorded in external magnetic field of $5 \mathrm{mT}$ for different ion fluencies is presented in Figure 19. The magnetization is affected by the radiation damage predominantly in the temperature region below the ferromagnetic $T_{C}$. The maximum of magnetization which is positioned at around $200 \mathrm{~K}$ is more than factor of two higher for the $2.5 \times 10^{17} \mathrm{ions} / \mathrm{cm}^{2}$ irradiated alloy that for that exposed to $5 \times 10^{15}$ ions $/ \mathrm{cm}^{2}$. Thus a strong dependence of magnetization upon the ion fluence is observed.

Hysteresis loops acquired for the ${ }^{57} \mathrm{Fe}_{75} \mathrm{Mo}_{8} \mathrm{Cu}_{1} \mathrm{~B}_{16}$ alloy after irradiation with $5 \times 10^{15}$ ions $/ \mathrm{cm}^{2}, 2 \times 10^{16}$ ions $/ \mathrm{cm}^{2}$, and $2.5 \times 10^{17}$ ions $/ \mathrm{cm}^{2}$ at $50 \mathrm{~K}$ and $300 \mathrm{~K}$ are depicted in Figure 20. The following observations should be mentioned. With increasing temperature of measurement, the maximum value of magnetization increases. Moreover, the shape of hysteresis loops is different at low values of the magnetizing field (up to $15 \mathrm{mT}$ ) for $50 \mathrm{~K}$ and $300 \mathrm{~K}$.

In order to inspect the variations in the shapes of hysteresis loops to more details, we have recorded them over

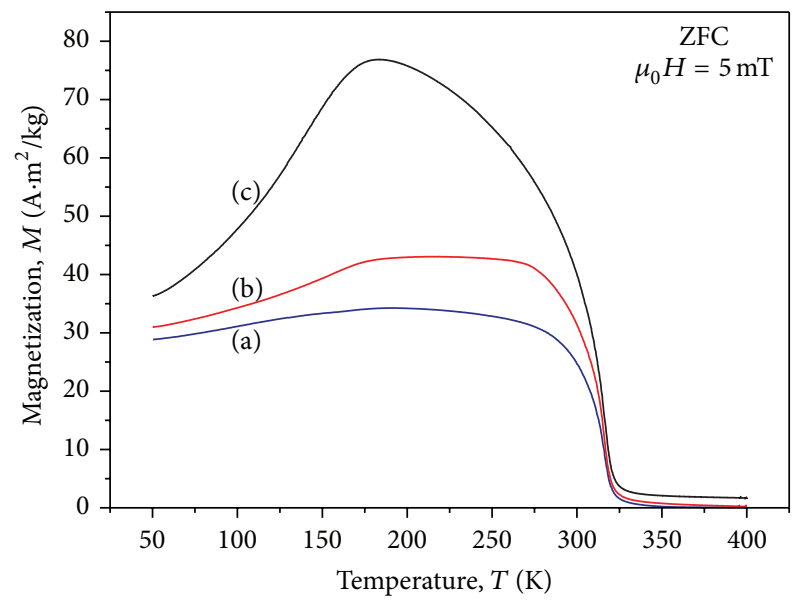

FIGURE 19: Zero field cooling magnetization measured in external magnetic field of $5 \mathrm{mT}$ plotted as a function of temperature for the

${ }^{57} \mathrm{Fe}_{75} \mathrm{Mo}_{8} \mathrm{Cu}_{1} \mathrm{~B}_{16}$ alloy after irradiation with $5 \times 10^{15}$ ions $/ \mathrm{cm}^{2}$ (a), 2 $\times 10^{16}$ ions $/ \mathrm{cm}^{2}(\mathrm{~b})$, and $2.5 \times 10^{17}$ ions $/ \mathrm{cm}^{2}$ (c).

wide temperature range from $50 \mathrm{~K}$ up to $400 \mathrm{~K}$. The obtained results are presented in Figure 21 for the $5 \times 10^{15}$ ions $/ \mathrm{cm}^{2}$ irradiated ${ }^{57} \mathrm{Fe}_{75} \mathrm{Mo}_{8} \mathrm{Cu}_{1} \mathrm{~B}_{16}$ alloy.

A linear dependence of magnetization versus magnetic field is observed for $T>T_{C}$ which is typical for paramagnetic materials. The same evolution of hysteresis loops with temperature was also observed for the alloys irradiated with $2 \times 10^{16}$ ions $/ \mathrm{cm}^{2}$ and $2.5 \times 10^{17}$ ions $/ \mathrm{cm}^{2}$ (not shown).

3.2.2. Annealed and Nanocrystalline Alloys. Distinctions between ion irradiated and annealed samples were checked also by magnetic measurements. Temperature dependencies of magnetization for the ${ }^{57} \mathrm{Fe}_{75} \mathrm{Mo}_{8} \mathrm{Cu}_{1} \mathrm{~B}_{16}$ alloy annealed at $643 \mathrm{~K}, 723 \mathrm{~K}$, and $783 \mathrm{~K}$ for $0.5 \mathrm{~h}$ are presented in Figure 22. Increase of magnetization as well as Curie temperature 


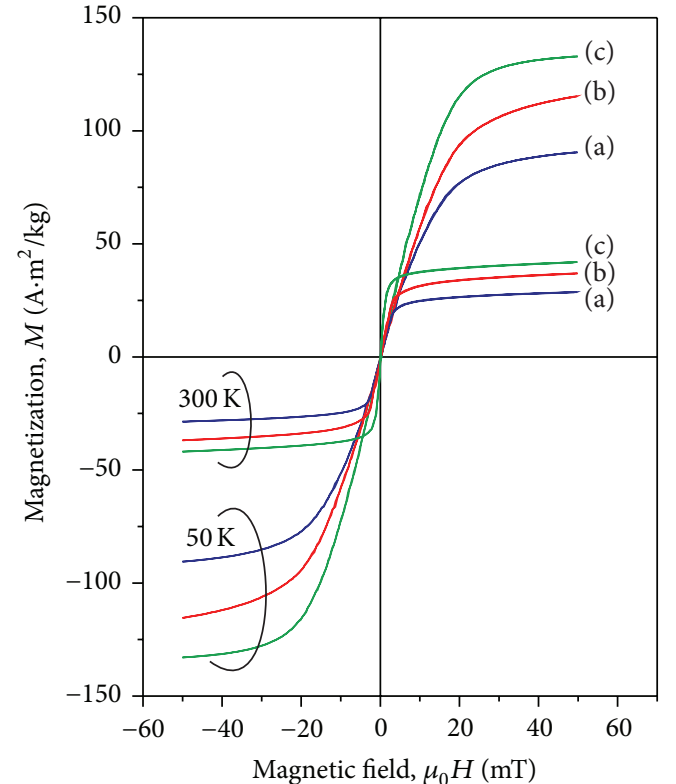

Figure 20: Hysteresis loops for the ${ }^{57} \mathrm{Fe}_{75} \mathrm{Mo}_{8} \mathrm{Cu}_{1} \mathrm{~B}_{16}$ alloy after irradiation with $5 \times 10^{15}$ ions $/ \mathrm{cm}^{2}$ (a), $2 \times 10^{16}$ ions $/ \mathrm{cm}^{2}$ (b), and 2.5 $\times 10^{17}$ ions $/ \mathrm{cm}^{2}$ (c) measured at temperature of $50 \mathrm{~K}$ and $300 \mathrm{~K}$.

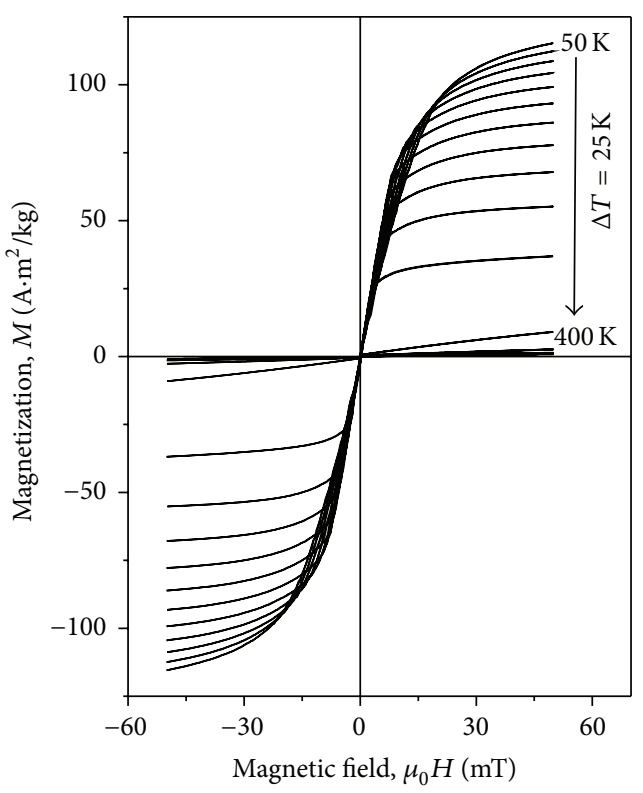

FIGURE 21: Hysteresis loops recorded in the temperature range 50$400 \mathrm{~K}$ with the step $\Delta T=25 \mathrm{~K}$ for the $5 \times 10^{15}$ ions $/ \mathrm{cm}^{2}$ irradiated ${ }^{57} \mathrm{Fe}_{75} \mathrm{Mo}_{8} \mathrm{Cu}_{1} \mathrm{~B}_{16}$ alloy.

is observed with annealing temperature. Both effects are ascribed to formation of bcc-Fe nanocrystals and to their amount.

Formation of bcc-Fe nanograins was confirmed by Mössbauer spectrometry. Their amount increases with annealing temperature. The resulting ferromagnetic exchange interactions among the bcc-Fe nanocrystals polarize also the

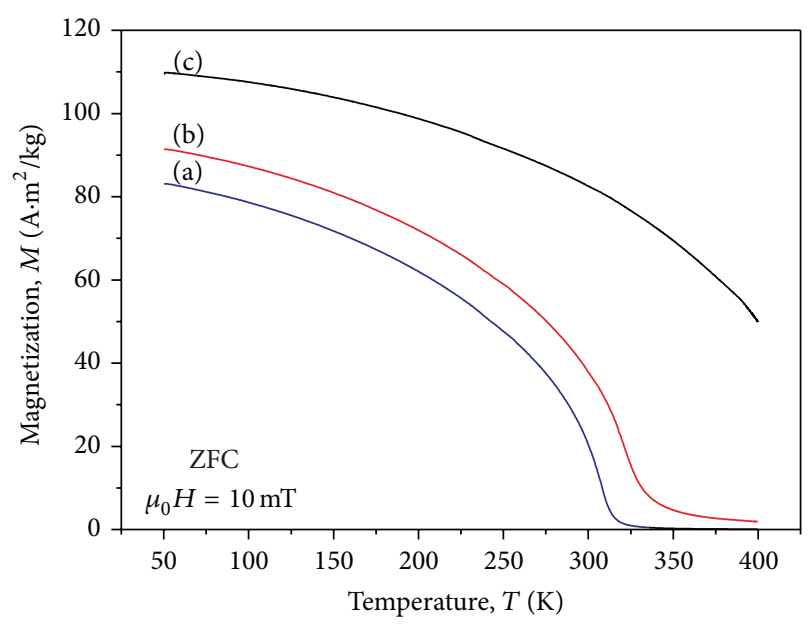

FIgURE 22: Zero field cooling magnetization measured in external magnetic field of $10 \mathrm{mT}$ plotted as a function of temperature for the ${ }^{57} \mathrm{Fe}_{75} \mathrm{Mo}_{8} \mathrm{Cu}_{1} \mathrm{~B}_{16}$ after $0.5 \mathrm{~h}$ annealing at $643 \mathrm{~K}(\mathrm{a}), 723 \mathrm{~K}(\mathrm{~b})$, and $783 \mathrm{~K}(\mathrm{c})$.

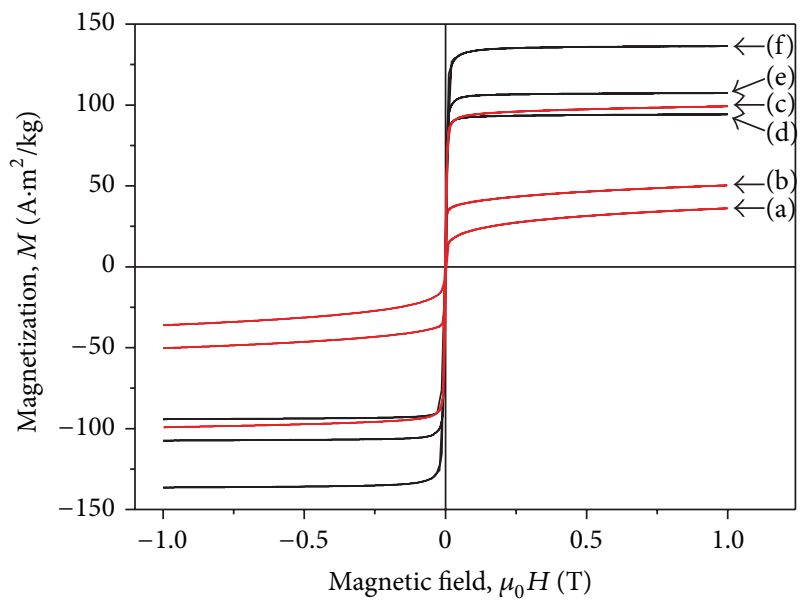

FIGURE 23: Hysteresis loops recorded at $300 \mathrm{~K}$ (a, b, c) and $50 \mathrm{~K}$ (d, e, f) for the ${ }^{57} \mathrm{Fe}_{75} \mathrm{Mo}_{8} \mathrm{Cu}_{1} \mathrm{~B}_{16}$ alloy after $0.5 \mathrm{~h}$ annealing at $643 \mathrm{~K} \mathrm{(a,}$ d), $723 \mathrm{~K}(\mathrm{~b}, \mathrm{e})$, and $783 \mathrm{~K}$ (c, f).

residual amorphous matrix. Consequently, enhanced contribution of magnetic interactions is observed. Nevertheless, using magnetic measurements, it is not possible to separate the inputs from structurally different regions (namely, nanocrystals, amorphous phase, and interface regions). We observe only integral behaviour over the whole bulk of the investigated alloys. Formation of nanocrystallites can be only deduced from different temperature dependence of magnetization which decreases more moderately for high enough annealing temperature (see curve (c) in Figure 22). Here, the contribution of bcc-Fe nanocrystals that exhibit high $T_{C}$ can be seen.

Figure 23 shows hysteresis loops recorded at room temperature $(300 \mathrm{~K})$ and $50 \mathrm{~K}$ for the annealed ${ }^{57} \mathrm{Fe}_{75} \mathrm{Mo}_{8} \mathrm{Cu}_{1} \mathrm{~B}_{16}$ samples. With increasing annealing temperature the maximum values of magnetization increase. Moreover, 
the magnetizations measured at $50 \mathrm{~K}$ show higher values than those that were taken at $300 \mathrm{~K}$ for the same samples.

\section{Conclusions}

The impact of ion irradiation upon structural modification and magnetic behaviour was studied in NANOPERM-type ${ }^{57} \mathrm{Fe}_{75} \mathrm{Mo}_{8} \mathrm{Cu}_{1} \mathrm{~B}_{16}$ alloy in amorphous and nanocrystalline states. Along with conventional magnetic measurements of temperature dependence of magnetization, Curie temperature, and hysteresis loops which provide integral information from the whole bulk of the investigated samples, the local probe method of Mössbauer spectrometry was also adopted. Namely, the techniques of CEMS and CXMS that make use of detection of conversion electrons and conversion X-rays were applied. CEMS and CXMS methods are capable of screening subsurface regions to the depths of $\sim 200 \mathrm{~nm}$ and $\sim 5-10 \mu \mathrm{m}$, respectively.

Ribbon-shaped samples were bombarded with $130 \mathrm{keV}$ $\mathrm{N}^{+}$ions to the total fluencies of up to $2.5 \times 10^{17}$ ions $/ \mathrm{cm}^{2}$ to their air sides. In order to assess the effect of temperature increase, different cooling modes were employed during ion irradiation. In addition, only heat treated samples were also investigated.

Ion irradiation has caused structural modifications that enhanced contribution of magnetic regions in originally weakly magnetic alloy. The ferromagnetic Curie temperature was increased from $313 \mathrm{~K}$ to $316 \mathrm{~K}$ after irradiation. No dependence of $T_{C}$ upon the ion fluence was observed even though the contribution of magnetic regions has increased with rising fluence. It should be noted, however, that this holds only for the air side which was exposed to ion bombardment. The opposite wheel side was practically intact.

The effects of ion irradiation were found to strongly depend upon the irradiation conditions, that is, thermal contact between the sample and cooled sample holder. Insufficient heat exchange has initiated partial nanocrystallization but again only at the air side. On the other hand, heat treatment without irradiation has caused production of nanocrystallites in the entire bulk of the samples with enhanced fraction of nanograins close to both surfaces of the ribbons.

The obtained results have pointed out a necessity of proper and careful assessment of experimental conditions and their impact upon the obtained results. It is also important to investigate structural modifications with depth sensitive methods. Local probe analytical tools can differentiate contributions from particular structural elements in complex (e.g., nanocrystalline) systems. This is not possible when macroscopic methods, which provide integral information over the entire bulk of the investigated materials, are employed.

\section{Conflict of Interests}

The authors declare that there is no conflict of interests regarding the publication of this paper.

\section{Acknowledgments}

The authors would like to thank M. Pavlovic for performing the SRIM calculations, S. Stanček for technical assistance with the ion irradiation, and M. Bujdoš for the determination the alloy's composition. This work was supported by the Research Grant GAČR 14-12449S.

\section{References}

[1] J. M. Perez, "Iron oxide nanoparticles: hidden talent," Nature Nanotechnology, vol. 2, no. 9, pp. 535-536, 2007.

[2] M. F. Ashby and A. L. Greer, "Metallic glasses as structural materials," Scripta Materialia, vol. 54, no. 3, pp. 321-326, 2006.

[3] A. Inoue and A. Takeuchi, "Recent development and application products of bulk glassy alloys," Acta Materialia, vol. 59, no. 6, pp. 2243-2267, 2011.

[4] G. Herzer, "Modern soft magnets: amorphous and nanocrystalline materials," Acta Materialia, vol. 61, no. 3, pp. 718-734, 2013.

[5] C. A. Schuh, T. C. Hufnagel, and U. Ramamurty, "Mechanical behavior of amorphous alloys," Acta Materialia, vol. 55, no. 12, pp. 4067-4109, 2007.

[6] P. Spiller, K. Blasche, B. Franczak et al., "Accelerator plans at GSI for plasma physics applications," Nuclear Instruments and Methods in Physics Research, Section A: Accelerators, Spectrometers, Detectors and Associated Equipment, vol. 544, no. 1-2, pp. 117124, 2005.

[7] R. Gerling and R. Wagner, "Properties of in-core reactorirradiated amorphous $\mathrm{Fe}_{40} \mathrm{Ni}_{40} \mathrm{~B}_{20}$, Journal of Nuclear Materials, vol. 107, no. 2-3, pp. 311-317, 1982.

[8] E. Kuzmann, M. Lakatos-Varsanyi, K. Nomura et al., "Combination of electrochemical hydrogenation and Mössbauer spectroscopy as a tool to show the radiation effect of energetic heavy ions in Fe-Zr amorphous alloys," Electrochemistry Communications, vol. 2, no. 2, pp. 130-134, 2000.

[9] K. V. Amrute, B. J. Nagare, R. P. Fernandes et al., "Modification of magnetic anisotropy in ferromagnetic metallic glasses using high energy ion beam irradiation," Surface and Coatings Technology, vol. 196, no. 1-3, pp. 135-138, 2005.

[10] R. Dubey, A. Gupta, P. Sharma, N. Darowski, and G. Schumacher, "Tailoring of magnetic anisotropy in amorphous and nanocrystalline soft magnetic alloys using swift heavy ions," Journal of Magnetism and Magnetic Materials, vol. 310, no. 2, pp. 2491-2493, 2007.

[11] K. K. Kadyrzhanov, M. F. Vereshchak, I. A. Manakova, A. N. Ozernoy, and V. S. Rusakov, "Structure-phase transformations in the Be-Fe-Be layered system subjected to irradiation and thermal treatment," Journal of Physics and Chemistry of Solids, vol. 74, no. 8, pp. 1078-1085, 2013.

[12] A. N. Ozernoy, M. F. Vereshchak, I. A. Manakova, K. K. Kadyrzhanov, and V. S. Rusakov, "Study of radiation-induced processes in a layered Be-Fe-Be system subjected to ion irradiation and subsequent isochronous annealings," The Physics of Metals and Metallography, vol. 115, no. 8, pp. 765-774, 2014.

[13] V. S. Kraposhin, V. S. Khmelevskaya, M. Y. Yazvitsky, and I. A. Antoshina, "Crystallization of Co-based amorphous alloys under the impact of the ion irradiation and recovery of the amorphous phase," Journal of Non-Crystalline Solids, vol. 353, no. 32-40, pp. 3057-3061, 2007. 
[14] M. Miglierini, A. Lančok, and M. Pavlovič, "Ion bombardment of Fe-based amorphous metallic alloys," Hyperfine Interactions, vol. 189, no. 1-3, pp. 45-52, 2009.

[15] D. G. Park, I. J. Lee, C. Y. Park, C. S. Angani, C. G. Kim, and Y. M. Cheong, "Ion-irradiation-induced effects on the magnetic properties of co-based amorphous ribbon," IEEE Transactions on Magnetics, vol. 46, no. 2, pp. 662-665, 2010.

[16] A. Gupta, S. Habibi, and G. Principi, "Study of short range order in Fe-Ni-Si-B amorphous alloys," Materials Science and Engineering A, vol. 304-306, no. 1-2, pp. 1058-1061, 2001.

[17] M. Miglierini, A. Lančok, and M. Pavlovič, "CEMS studies of structural modifications of metallic glasses by ion bombardment," Physics of Metals and Metallography, vol. 109, no. 5, pp. 469-474, 2010.

[18] M. E. McHenry and D. E. Laughlin, "Nano-scale materials development for future magnetic applications," Acta Materialia, vol. 48, no. 1, pp. 223-238, 2000.

[19] K. Suzuki and G. Herzer, "Magnetic-field-induced anisotropies and exchange softening in Fe-rich nanocrystalline soft magnetic alloys," Scripta Materialia, vol. 67, no. 6, pp. 548-553, 2012.

[20] Y. Yoshizawa, S. Oguma, and K. Yamauchi, "New Fe-based soft magnetic alloys composed of ultrafine grain structure," Journal of Applied Physics, vol. 64, no. 10, pp. 6044-6046, 1988.

[21] K. Suzuki, N. Kataoka, A. Inoue, A. Makino, and T. Masumoto, "High saturation magnetization and soft magnetic properties of bcc Fe-Zr-B alloys with ultrafine grain structure," Materials Transactions, JIM, vol. 31, no. 8, pp. 743-746, 1990.

[22] M. A. Willard, D. E. Laughlin, M. E. McHenry et al., "Structure and magnetic properties of $\left(\mathrm{Fe}_{0.5} \mathrm{Co}_{0.5}\right)_{88} \mathrm{Zr}_{7} \mathrm{~B}_{4} \mathrm{Cu}_{1}$ nanocrystalline alloys," Journal of Applied Physics, vol. 84, no. 12, pp. 6773-6777, 1998

[23] D. Alloyeau, C. R. Mottet, and C. Ricolleau, Eds., NanoalloysSynthesis, Structure and Properties, Springer, London, UK, 2012.

[24] R. Hasegawa, "Advances in amorphous and nanocrystalline materials," Journal of Magnetism and Magnetic Materials, vol. 324, no. 21, pp. 3555-3557, 2012.

[25] Š. Michalik, J. Michaliková, M. Pavlovič, P. Sovák, H. Liermann, and M. Miglierini, "Structural modifications of swiftion-bombarded metallic glasses studied by high-energy X-ray synchrotron radiation," Acta Materialia, vol. 80, pp. 309-316, 2014.

[26] M. Miglierini, T. Kaňuch, T. Krenický, and I. Škorvánek, “Magnetic and Mössbauer studies of $\mathrm{Fe}_{76} \mathrm{Mo}_{8} \mathrm{Cu}_{1} \mathrm{~B}_{15}$ nanocrystalline alloy," Czechoslovak Journal of Physics, vol. 54, no. 4, pp. D73D76, 2004.

[27] M. Miglierini, J. Kohout, A. Lančok, and K. Šafářová, "Magnetic hyperfine fields of nanoperm alloys," Acta Physica Polonica A, vol. 121, no. 5-6, pp. 1263-1265, 2012.

[28] M. Miglierini and J.-M. Greneche, "Mössbauer spectrometry of $\mathrm{Fe}(\mathrm{Cu}) \mathrm{MB}$-type nanocrystalline alloys: I. The fitting model for the Mössbauer spectra," Journal of Physics Condensed Matter, vol. 9, no. 10, pp. 2303-2319, 1997.

[29] M. Miglierini and J.-M. Grenèche, "Temperature behaviour of iron nanograins in NANOPERM-type alloys," Journal of Physics Condensed Matter, vol. 15, no. 32, pp. 5637-5648, 2003.

[30] M. Pavlovič and I. Strašík, "Supporting routines for the SRIM code," Nuclear Instruments and Methods in Physics Research Section B, vol. 257, pp. 601-604, 2007.

[31] T. Žák and Y. Jirásková, “CONFIT: Mössbauer spectra fitting program," Surface and Interface Analysis, vol. 38, no. 4, pp. 710714, 2006.
[32] M. Hasiak, M. Miglierini, J. Kaleta, and M. Bujdoš, "Magnetocaloric properties of $\mathrm{Fe}_{75} \mathrm{Mo}_{8} \mathrm{Cu}_{1} \mathrm{~B}_{16}$ and $\mathrm{Fe}_{81} \mathrm{Mo}_{8} \mathrm{Cu}_{1} \mathrm{~B}_{10}$ metallic glasses," Acta Physica Polonica A, vol. 127, no. 2, pp. 608-610, 2015.

[33] M. Miglierini, M. Kopcewicz, B. Idzikowski et al., "Structure, hyperfine interactions, and magnetic behavior of amorphous and nanocrystalline $\mathrm{Fe}_{80} \mathrm{M}_{7} \mathrm{~B}_{12} \mathrm{Cu}_{1}(\mathrm{M}=\mathrm{Mo}, \mathrm{Nb}, \mathrm{Ti})$ alloys," Journal of Applied Physics, vol. 85, no. 2, pp. 1014-1025, 1999. 

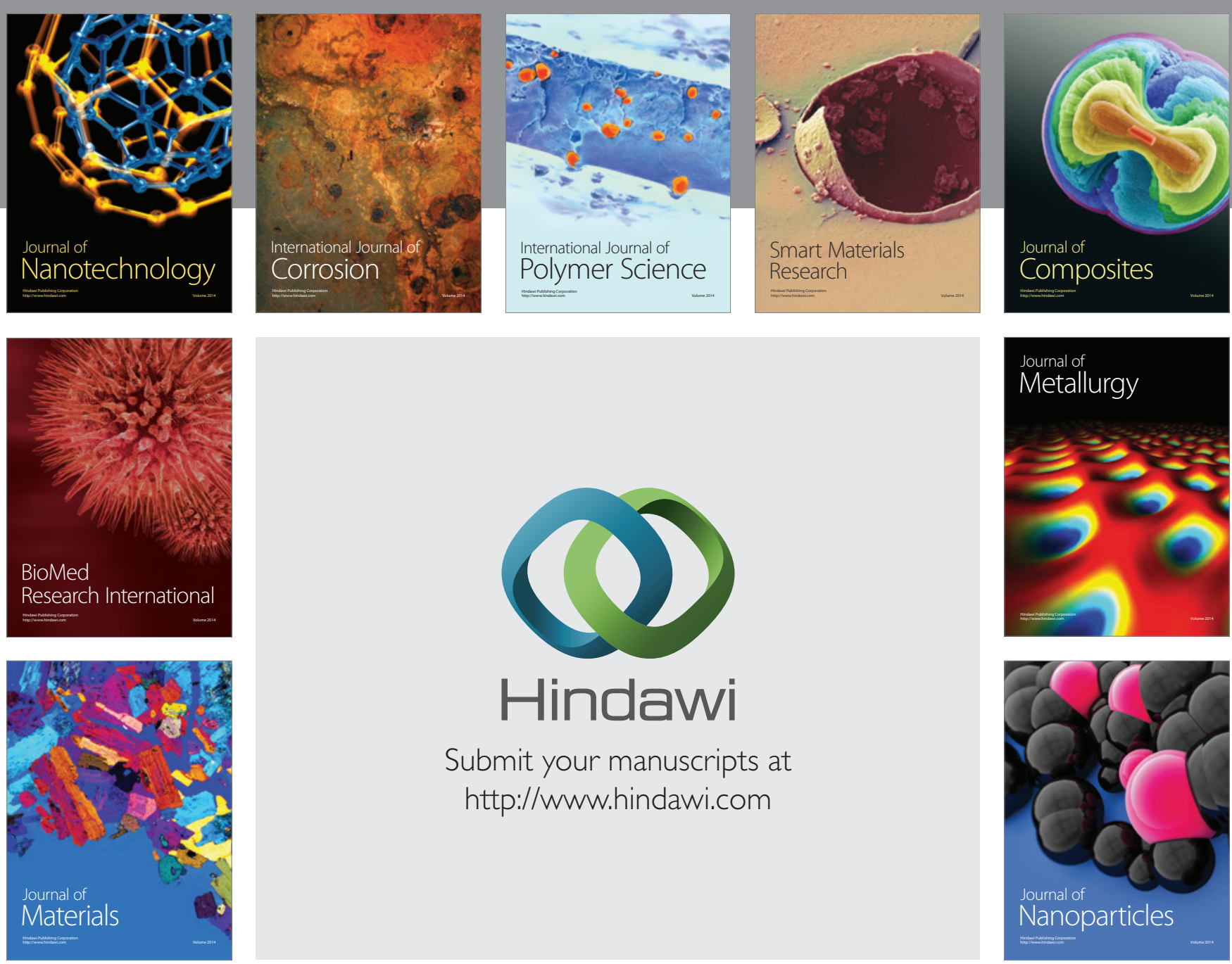

Submit your manuscripts at http://www.hindawi.com
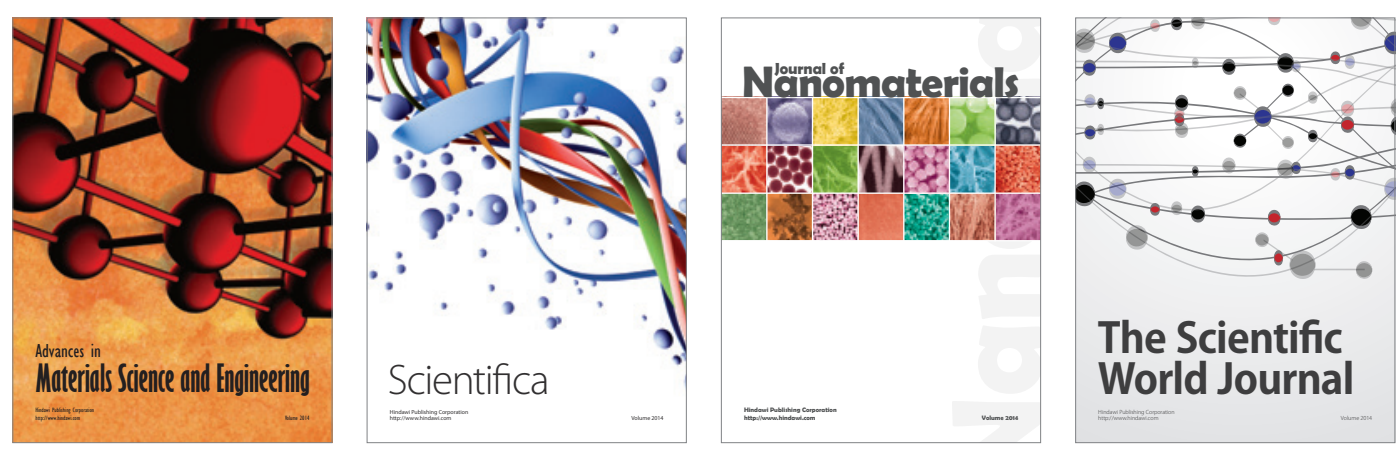

\section{The Scientific World Journal}
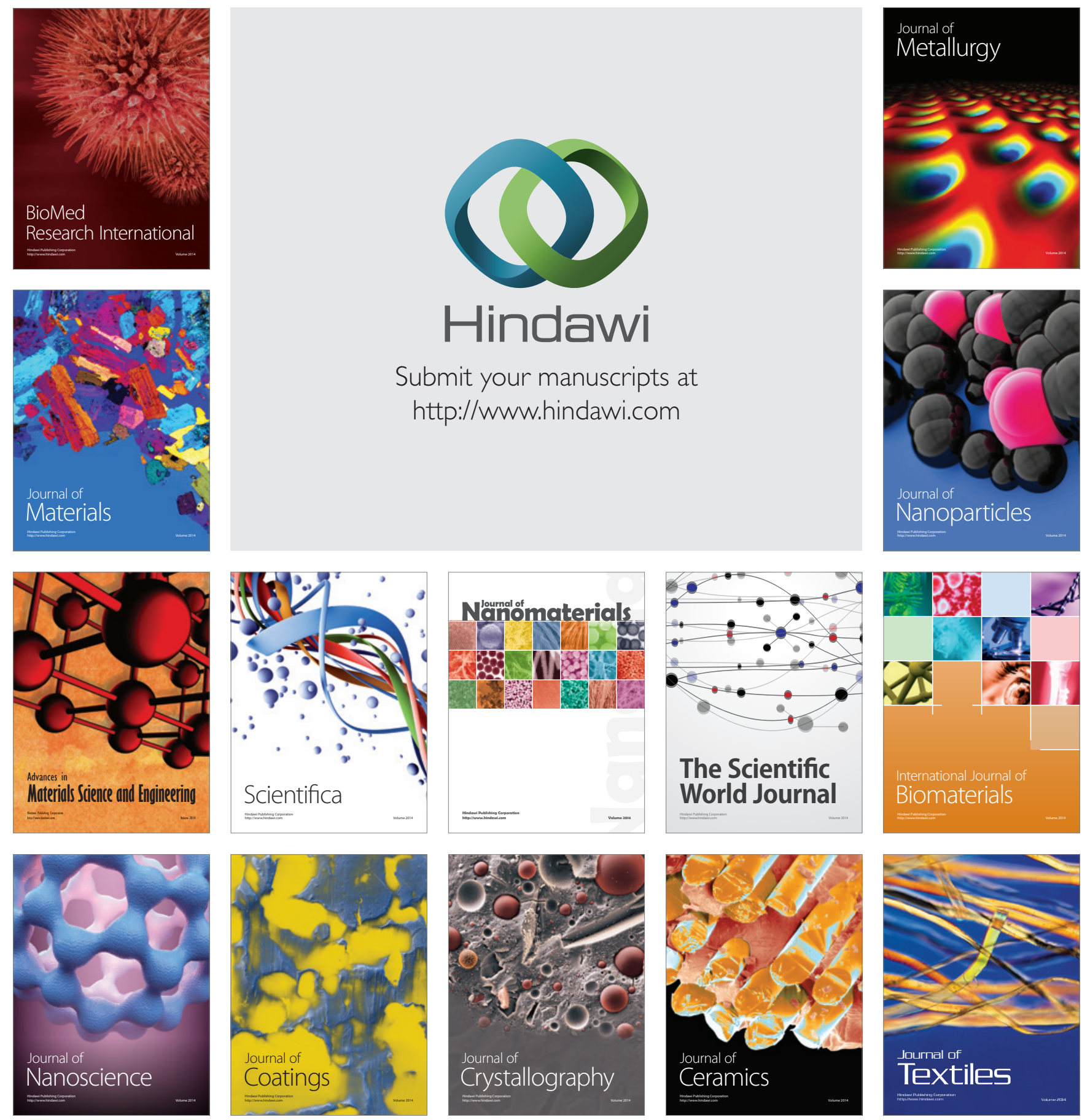